\title{
EL DELITO ECOLÓGICO DEL ARTÍCULO 325 DEL CÓDIGO PENAL
}

\author{
LuZ MARÍA PUENTE ABA \\ Profesora contratada doctora de Derecho penal \\ Universidade da Coruña \\ lpuente@udc.es
}

Recibido: 16 de diciembre de 2011 / Aceptado: 23 de mayo de 2011

RESUMEN: Este trabajo ofrece un análisis del artículo 325 del Código penal; se trata de la figura básica del delito ecológico, contenida en el inciso primero, y de la figura incluida en el inciso segundo, que aquí se califica como tipo autónomo del anterior. Se efectúa un examen de todos los elementos típicos, y asimismo de las diversas formas de aparición de los delitos: determinación del momento de consumación, cuestiones problemáticas en el marco de la autoría y participación, y análisis de las posibles situaciones concursales que pueden plantearse. Tal exégesis se efectúa teniendo en cuenta el desarrollo de la práctica de los Tribunales en relación con este precepto; se pretende poner de relieve las cuestiones más problemáticas en su aplicación, y ofrecer diversas pautas interpretativas al respecto.

RESUMEN: Aquest treball ofereix una anàlisi de l'article 325 del Codi penal; es tracta de la figura bàsica del delicte ecològic, continguda en l'incís primer, i de la figura inclosa en l'incís segon, que aquí es qualifica com a tipus autònom de l'anterior. S'efectua un examen de tots els elements típics i, així mateix, de les diferents formes d'aparició dels delictes: determinació del moment de consumació, qüestions problemàtiques en el marc de l'autoria i participació, i anàlisi de les possibles situacions concursals que puguin plantejar-se. Aquesta exègesi es du a terme tenint en compte el desenvolupament de la pràctica dels Tribunals en relació amb aquest precepte; es pretén 
posar de manifest les qüestions més problemàtiques en la seva aplicació, i oferir diverses pautes interpretatives en relació amb això.

\begin{abstract}
This paper offers an analysis of the article 325 of the Penal Code; here it is the basic offence of ecological crime, contained in the first phrase, and the offence included in the second phrase, that is considered here as an autonomous offence in relation with the previous one. It is made a study of all the elements of the offences, as well as a vision of the different forms of the infractions: determination of the moment of perpetration, problematic questions related with the authorship and cooperation in the offence, and analysis of the different concurrences of offences that could appear. This study is made taking into account the practice of the courts; it pretends to point out the most problematic questions in the enforcement of the norm, and to offer interpretative criteria.
\end{abstract}

PALABRAS CLAVE: Delito ecológico — Derecho penal ambiental - criminalidad medioambiental.

PARAULES CLAU: Delicte ecològic - Dret penal ambiental - criminalitat ambiental.

KEY WORDS: Ecological crime - Environmental Criminal Law - environmental criminality 
Sumario: I. Introducción. II. Breve referencia al bien jurídico protegido y a los sujetos pasivo y activo. III. La conducta típica. 1. La figura básica del delito ecológico: el inciso $1^{\circ}$ del artículo 325. 1.1. La vulneración de la normativa protectora del medio ambiente. 2.1. La posibilidad de perjudicar gravemente el equilibrio de los sistemas naturales. 2. El tipo autónomo por el riesgo para la salud de las personas: el inciso $2^{\circ}$ del artículo 325. IV. El tipo subjetivo. V. La consumación. VI. Autoría y participación. 1. Determinación de la responsabilidad penal en el ámbito empresarial. 2. Concurrencia de diferentes sujetos en la realización del hecho delictivo. Especial referencia a los casos de autoría accesoria. VII. Las consecuencias jurídicas. VIII. Situaciones concursales. IX. Bibliografía.

\section{INTRODUCCIÓN}

Este trabajo pretende ofrecer un análisis pormenorizado del artículo 325 del Código penal, figura inicial en el marco de los delitos contra el medio ambiente. Este precepto fue modificado por la Ley Orgánica 5/2010, de 22 de junio, por la que se reforma el Texto punitivo. Indudablemente, tal reforma tiene el acierto de eliminar el párrafo segundo del precepto, relativo a la emisión de radiaciones ionizantes u otras sustancias contaminantes que, por un lado, tantos problemas concursales había creado con otras figuras delictivas existentes en el Código penal (v.gr. los delitos relativos a la energía nuclear y a las radiaciones ionizantes) ${ }^{1}$, y por otro lado, nada añadía a la amplia figura contenida en el párrafo primero ${ }^{2}$.

Consecuentemente, nos encontramos de nuevo con un artículo 325 que recoge la figura básica de los delitos contra el medio ambiente, el denominado "delito ecológico", en su inciso primero; y en el inciso segundo, se contiene una variante de tal tipo delictivo que, como se verá, no recibe una calificación unánime: para unos, un tipo agravado del delito ecológico, y para otros, un tipo autónomo que comparte casi todos sus elementos típicos con el inciso primero, excepto uno (el peligro típico) que lo singulariza como tipo autónomo.

El objetivo de este trabajo es examinar los elementos típicos de ambas figuras del artículo 325, con especial referencia a su aplicación jurisprudencial, poniendo de relieve las diversas particularidades e interrogantes que pueden plantearse al interpretar y aplicar estos delitos: por ejemplo, cómo constatar la existencia de un peligro grave para

\footnotetext{
${ }^{1}$ Señalan el acierto de esta reforma MUÑOZ LORENTE, J. / BAUCELLS LLADÓS, J. / FARALDO CABANA, P., "Delitos contra los recursos naturales y el medio ambiente (arts. 325, 327, 328 y 329)", Álvarez García, F.J. / González Cussac, J.L. (dir.), Comentarios a la Reforma Penal de 2010, Tirant lo Blanch, Valencia, 2010, pp. 387-388.

${ }^{2}$ Los otros puntos en los que el artículo 325 fue afectado por la citada reforma son los siguientes: agravación de la pena de prisión, e introducción de la mención expresa del "alta mar" como lugar donde puede verificarse la contaminación delictiva.
} 
el medio ambiente (lo cual pasa, obviamente, por descifrar a qué se refiere el Texto punitivo al referirse a los "sistemas naturales", y que plantea sin duda numerosas preguntas: ¿es necesaria la efectiva destrucción de elementos del medio ambiente?, o ¿qué requisitos ha de reunir el riesgo para ser considerado "grave"?); qué relevancia han de tener los posibles errores en los que puede incurrir el sujeto activo del delito; cómo identificar a los autores del delito (v.gr. en casos de comisión de la infracción en el marco de una estructura empresarial, o cuando concurren simultáneamente actos de contaminación procedentes de diversos sujetos), etc.

\section{BREVE REFERENCIA AL BIEN JURÍDICO PROTEGIDO Y A LOS SUJETOS PASIVO Y ACTIVO}

De entrada, es evidente que el bien jurídico protegido en el artículo 325 del Código penal está constituido por el "medio ambiente", expresión que figura en la rúbrica del Capítulo que contiene esta figura delictiva. Las discrepancias surgen en el momento de otorgar significado a esta expresión, y en esta línea pueden reconocerse de entrada dos concepciones contrapuestas ${ }^{3}:$ la consideración del medio ambiente desde un punto de vista "ecocéntrico", que defiende que el medio ambiente ha de tutelarse como valor en sí mismo considerado, y, bajo otra perspectiva, desde una visión "antropocéntrica", que justifica la protección del medio ambiente por la necesidad de mantener las condiciones necesarias para el correcto y adecuado desarrollo de bienes jurídicos de naturaleza individual, de modo que su afectación merece ser sancionada en la medida en que suponga un daño o puesta en peligro de valores básicos del individuo, concretamente la vida y la salud de las personas.

La doctrina por lo general oscila entre un antropocentrismo moderado y un ecocentrismo también moderado; por una parte, el punto de partida fundamental de las posturas antropocéntricas se halla en el artículo 45 de la Constitución, que establece el

\footnotetext{
${ }^{3}$ Parece que hay acuerdo sobre su aspecto estrictamente físico, natural o biológico, excluyendo otros aspectos relacionados con el entorno o las condiciones vitales del ser humano, como la salud pública, la ordenación del territorio, etc. Vid. por ejemplo al respecto BLANCO LOZANO, C., La protección del medio ambiente en el Derecho penal español y comparado, Comares, Granada, 1997, p. 39; COLÁS TURÉGANO, A., "Algunas consideraciones sobre los delitos contra el medio ambiente en el CP de 1995 (C. III del T. XVI del L. II)", AAVV, Estudios jurídicos en memoria del profesor Dr. D. José Ramón Casabó Ruiz, Universidad de Valencia, 1997, Volumen I, pp. 435-436; GÓMEZ RIVERO, M.C., "El delito ecológico", Martos Núñez, J.A. (dir.), Derecho penal ambiental, Exlibris, Madrid, 2006, p. 65; MATELLANES RODRÍGUEZ, N., Derecho penal del medio ambiente, Iustel, Madrid, 2008, pp. 40-41.
} 
derecho a disfrutar de un "medio ambiente adecuado para el desarrollo de la persona" 4 , y por otra parte, la inclinación hacia una línea ecocéntrica se centra, fundamentalmente, en la actual redacción del delito ecológico en el Código penal de 1995, que se refiere a la protección de "los recursos naturales y el medio ambiente" 5 .

Sin intención de entrar en un análisis pormenorizado de esta cuestión, puede afirmarse que tanto el antropocentrismo moderado como el ecocentrismo moderado suelen

\footnotetext{
${ }^{4}$ Vid. así, siguiendo una postura primordialmente antropocéntrica, BOIX REIG, J. / JAREÑO LEAL, A., "De los delitos contra los recursos naturales y el medio ambiente", Vives Antón, T.S. (coord.), Comentarios al Código Penal de 1995, Volumen I, Tirant lo Blanch, Valencia, 1996, pp. 1592; GARCíA RIVAS, N., Delito ecológico. Estructura y aplicación judicial, Praxis, Barcelona, 1998, p. 125; HORMAZÁBAL MALAREE, H., "El principio de lesividad y el delito ecológico", Quintero Olivares, G. / Morales Prats, F. (coord.), El nuevo Derecho penal español. Estudios penales en memoria del Profesor José Manuel Valle Muñiz, Aranzadi, Cizur Menor, 2001, p. 1425; JORGE BARREIRO, A., "El bien jurídico protegido en los delitos contra el medio ambiente en el CP de 1995", Jorge Barreiro, A. (dir.), Estudios sobre la protección penal del medio ambiente en el ordenamiento jurídico español, Comares, Granada, 2005, pp. 1 ss; MARTÍNEZ-BUJÁN PÉREZ, C., Derecho penal económico y de la empresa. Parte especial, Tirant lo Blanch, Valencia, $2011^{3}$, p. 796; MATELLANES RODRÍGUEZ, Derecho penal cit., pp. 38-39; MORALES PRATS, F., "La estructura del delito de contaminación ambiental. Dos cuestiones básicas: la ley penal en blanco y concepto de peligro", AAVV, Estudios jurídicos en memoria del profesor Dr. D. José Ramón Casabó Ruiz, Universidad de Valencia, 1997, p. 497; SILVA SÁNCHEZ, J.M., Delitos contra el medio ambiente, Tirant lo Blanch, Valencia, 1999, pp. 17-18; SOSPEDRA NAVAS, F., "De los delitos contra los recursos naturales y el medio ambiente. Capítulo III", Domínguez, J.A. y otros, Delitos relativos a la ordenación del territorio y protección del patrimonio histórico, medio ambiente y contra la seguridad colectiva (delitos de riesgo catastrófico e incendios), Bosch, Barcelona, 1999, p. 170; VERCHER NOGUERA, A., "Responsabilidad penal ambiental", Vercher Noguera, A. / Díez-Picazo Giménez, G. / Castañón del Valle, M., Responsabilidad ambiental penal, civil y administrativa, La Ley, Madrid, 2003, pp. 22 ss. Ponen de relieve la importancia de la visión antropocéntrica en la doctrina, CORCOY BIDASOLO, M., "Protección penal del medio ambiente: legitimidad y alcance. Competencia penal y administrativa", Mir Puig, S. / Modolell González, J.L. I Gallego Soler, J.I. / Bello Rengifo, C.S. (coord.), Estudios de Derecho penal económico, Livrosca, Caracas, 2002, p. 613; DE LA MATA BARRANCO, N., "El ambiente, como objeto de tutela penal específico y sistemáticamente autónomo, desde una concepción moderadamente antropocéntrica", Mir Puig, S. / Modolell González, J.L. / Gallego Soler, J.I. / Bello Rengifo, C.S. (coord.), Estudios de Derecho penal económico, Livrosca, Caracas, 2002, p. 578.
}

5 Vid. siguiendo una línea "ecocéntrica" (en este caso no moderada), MARTOS NÚÑEZ, J.A., "Introducción al Derecho penal ambiental", Martos Núñez, J.A. (dir.), Derecho penal ambiental, Exlibris, Madrid, 2006, pp. 29-30. Por lo general, partiendo de una línea ecocéntrica, se pone de relieve que aun desde esta perspectiva la protección del medio ambiente tiene como último punto de referencia la tutela del ser humano: ALASTUEY DOBÓN, M.C., El delito de contaminación ambiental (artículo 325.1 del Código penal), Comares, Granada, 2004, pp. 36 ss; DE LA CUESTA ARZAMENDI, J.L., "Cuestiones dogmáticas relativas al delito de contaminación ambiental", Revista penal, núm. 4, 1999, p. 32; GÓMEZ RIVERO, "El delito ecológico" cit., pp. 66-67. Ponen de relieve la generalización progresiva de la postura ecocéntrica en la doctrina: ESCAJEDO SAN EPIFANIO, L., El medio ambiente en la crisis del Estado social. Su protección penal simbólica, Ecorama, Granada, 2006, pp. 323-325; GÓMEZ RIVERO, "El delito ecológico" cit., pp. 66-67; DE LA MATA BARRANCO, N., "Protección penal del ambiente", Serrano Piedecasas, J.R. / Demetrio Crespo, J.R. (dir.), Cuestiones actuales de Derecho penal empresarial, Colex, Madrid, 2010, p. 7457; RODRÍGUEZ LÓPEZ, P., Medio ambiente, territorio, urbanismo y Derecho penal, Bosch, Barcelona, 2007, p. 269; TERRADILLOS BASOCO, J., "Delitos relativos a la protección del patrimonio histórico y del medio ambiente", Terradillos Basoco, J. (ed.), Derecho penal del medio ambiente, Trotta, Madrid, 1997, pp. 42-43. Vid. en JORGE BARREIRO, "El bien jurídico protegido" cit., pp. 38 ss, un resumen sobre las distintas posturas doctrinales en torno al bien jurídico. 
coincidir, como se acaba de ver, en tener como punto de referencia al ser humano y a los bienes jurídicos individuales, ya sea considerándolos como fundamento esencial del bien jurídico medio ambiente, o ya sea entendiendo que los bienes personales son el último punto de referencia del medio ambiente, aun considerándolo como un interés totalmente independiente. En el fondo, no puede olvidarse que el valor del medio ambiente no puede separarse de su carácter de condición y presupuesto necesarios para el adecuado desarrollo de la vida humana, y que el ser humano como tal es un elemento más del ecosistema natural, y una protección del medio ambiente siempre redundará en beneficio de bienes jurídicos individuales como la vida o la salud de las personas.

En cuanto al sujeto pasivo de este delito, en consonancia con la naturaleza colectiva del bien jurídico "medio ambiente", está constituido por la colectividad en general, por el conjunto de miembros de la comunidad social ${ }^{6}$. En relación con el sujeto activo, no existe ninguna particularidad digna de mención: se trata de un delito común, de tal modo que cualquier persona puede cometerlo.

\section{LA CONDUCTA TÍPICA}

\section{La figura básica del delito ecológico: el inciso $1^{\circ}$ del artículo 325.}

La conducta castigada en el primer inciso del artículo 325 consiste en la provocación o realización directa o indirecta de emisiones, vertidos, radiaciones, extracciones o excavaciones, aterramientos, ruidos, vibraciones, inyecciones o depósitos, en la atmósfera, el subsuelo, el suelo o las aguas terrestres, subterráneas o marítimas, incluido el alta mar, con incidencia incluso en los espacios transfronterizos, así como en la realización de captaciones de aguas ${ }^{7}$. La verificación de alguna de estas conductas ha de venir acompañada por dos requisitos típicos adicionales: que se estén vulnerando las

\footnotetext{
${ }^{6}$ Vid. por ej., BLANCO LOZANO, C., El delito ecológico. Manual operativo, Montecorvo, Madrid, 1997, p. 68.

${ }^{7}$ Vid. por ejemplo, analizando el significado de cada una de las mencionadas conductas, BAUCELLS LLADÓS, J., "De los delitos relativos a la ordenación del territorio y la protección del patrimonio histórico y del medio ambiente", Córdoba Roda, J. / García Arán, M. (dir.), Comentarios al Código Penal. Parte especial. Tomo I, Marcial Pons, Madrid, 2004, pp. 1385-1387; BLANCO LOZANO, La protección cit., pp. 207 ss; MENDO ESTRELLA, A., El delito ecológico del artículo 325.1 del Código penal, Tirant lo Blanch, Valencia, 2009, pp. 65 ss; RODRÍGUEZ LÓPEZ, Medio ambiente cit., pp. 324 ss; SILVA SÁNCHEZ, Delitos cit., pp. 40 ss; VAELLO ESQUERDO, E., "Los delitos contra el medio ambiente", Revista Aranzadi de Derecho Ambiental, núm.7, 2005-1, pp. 23 ss.
} 
leyes $\mathrm{u}$ otras disposiciones generales protectoras del medio ambiente, y que se constate la posibilidad de perjudicar gravemente el equilibrio de los sistemas naturales.

En este punto merece especial mención la referencia al "alta mar", introducida por la LO 5/2010, de 22 de junio, de reforma del Código penal. Si bien el artículo 325 ya incluía la contaminación realizada en aguas marítimas, la introducción del "alta mar" fue motivada por las Directivas 2005/35/CE y 2009/123/CE, relativas a la contaminación procedente de buques, que pretendían reforzar la legislación penal de los Estados ante los graves casos de polución causada por vertidos de buques en las aguas marítimas. En cualquier caso, esta referencia al alta mar no tiene por qué ceñirse a estos únicos supuestos, ya que serían imaginables hipótesis de contaminación de este tipo de aguas mediante vertidos procedentes de zonas $\operatorname{costeras}^{8}$. El problema que plantea esta mención es que se está refiriendo a la contaminación producida en un área que no está bajo la soberanía de ningún Estado. Evidentemente, y siguiendo la teoría de la ubicuidad, no habrá problema en defender la jurisdicción del Estado español cuando la contaminación haya alcanzado alguna zona de su territorio, ya sea marítimo o terrestre ${ }^{9}$; sin embargo, cabe plantearse qué puede suceder en los casos en que la conducta delictiva tenga sólo efectos en alta mar y procede de un buque que no sea de nacionalidad española. Ya en su momento se criticó que la mención en el artículo 325 de los "espacios transfronterizos" no resultaba adecuada, puesto que no era la vía para eliminar problemas de impunidad o de falta de competencia de los Tribunales, y que en todo caso lo procedente sería reformar el artículo 23 de la Ley Orgánica del Poder Judicial, que contempla las excepciones al principio de territorialidad ${ }^{10}$. Sin embargo, aun procediendo a reformar el citado artículo 23, y fundamentalmente el principio de justicia universal, habría que tener en cuenta la existencia de la Convención de la ONU sobre el Derecho del Mar (Montego Bay, 1982), que establece en su artículo 97 que, en caso de cualquier incidente ocurrido en un buque en alta mar que determine responsabilidad penal de alguno de sus tripulantes, sólo podrán incoarse procedimientos

\footnotetext{
${ }^{8}$ Vid. MUÑOZ LORENTE / BAUCELLS LLADÓS / FARALDO CABANA, "Delitos" cit, p. 387; y MARTÍNEZ-BUJÁN PÉREZ, Derecho penal económico cit., p. 797, citando específicamente el caso de contaminación marítima provocado por la empresa BP en el Golfo de México.

${ }^{9}$ Vid. al respecto COCOY BIDASOLO, M., “Artículo 325”, Corcoy Bidasolo, M. / Mir Puig, S. (dir.), Comentarios al Código penal. Reforma LO 5/2010, Tirant lo Blanch, Valencia, 2011, pp. 738-739; SILVA SÁNCHEZ, Delitos cit., p. 47.

${ }^{10}$ Vid. CORCOY BIDASOLO, “Artículo 325” cit., pp. 607-608; SILVA SÁNCHEZ, Delitos cit., pp. 4748.
} 
penales o disciplinarios por parte del Estado del pabellón o del Estado de nacionalidad de dichas personas; y asimismo en su artículo 230 se dispone que las infracciones de leyes nacionales destinadas a controlar la contaminación, cometidas por buques extranjeros fuera del mar territorial, sólo podrán dar lugar a la imposición de sanciones pecuniarias $^{11}$.

La conducta indudablemente está descrita de una forma casuística, y realmente podría concluirse que se castiga la realización de un acto de contaminación que afecte a la atmósfera, al agua, al suelo o al subsuelo. De hecho, hubiera sido preferible que la conducta típica fuera definida como "acto de contaminación", puesto que se trata de una expresión suficientemente omnicomprensiva, y al menos constituye una técnica mejor que las largas enumeraciones, que siempre generan el riesgo de dejar fuera del ámbito típico alguna conducta que también afecte negativamente al medio ambiente ${ }^{12}$. Estamos por lo tanto ante un delito de resultado material, es decir, debe constatarse una efectiva alteración del elemento medioambiental afectado por la conducta contaminante ${ }^{13}$. Por consiguiente, será necesario determinar la relación de causalidad entre la conducta concreta (v.gr. el vertido de materiales sólidos o líquidos a las aguas) y el concreto resultado físico-natural producido (v.gr. la modificación sufrida por las aguas receptoras del vertido $)^{14}$. Dado que estamos ante un delito de resultado, es admisible su comisión por omisión ${ }^{15}$. Debe tenerse en cuenta que la provocación de los diversos resultados se

\footnotetext{
11 Vid. también sobre las limitaciones que impone esta normativa internacional a la jurisdicción del Estado en el mar territorial y en la zona económica exclusiva, PUENTE ABA, L.M. / PERNAS GARCÍA, J.J., "Le Droit répressif espagnol et les déversements illicites des navires en mer", Le Droit maritime français, núm. 661, 2005, pp. 635-638.

${ }^{12}$ Vid. críticamente en relación con esta técnica casuística, CORCOY BIDASOLO, "Protección penal" cit., pp. 626 ss, y “Artículo 325” cit., p. 738; MATA Y MARTÍN, R.M., “Artículo 325”, Gómez Tomillo, M. (dir.), Comentarios al Código penal, Lex Nova, Valladolid, $2011^{2}$, p. 1271.

${ }^{13}$ Vid. CORCOY BIDASOLO, “Artículo 325” cit., p. 740; MARTÍNEZ-BUJÁN PÉREZ, Derecho penal económico cit., p. 797; SILVA SÁNCHEZ, Delitos cit., pp. 23-24.

${ }^{14}$ Cfr. AlASTUEY DOBÓN, El delito cit., p. 118; CORCOY BIDASOLO, "Protección penal" cit., p. 631; MARTÍNEZ-BUJÁN PÉREZ, Derecho penal económico cit., p. 797. Pueden verse específicamente sobre esta cuestión, DE LA CUESTA AGUADO, P., Causalidad en los delitos contra el medio ambiente, Tirant lo Blanch, Valencia, 1999, pássim; LLORENTE SÁNCHEZ-ARJONA, M., "La prueba de la relación de causalidad en los daños ambientales", Martos Núñez, J.A. (dir.), Derecho penal ambiental, Exlibris, Madrid, 2006, pp. 315 ss.

${ }^{15}$ Cfr. BLANCO LOZANO, La protección del medio ambiente cit., pp. 215-216; CORCOY BIDASOLO, “Artículo 325" cit., p. 738; GÓMEZ RIVERO, "El delito ecológico" cit., p. 70; MARTÍNEZ-BUJÁN PÉREZ, Derecho penal económico cit., p. 798; MUÑOZ CONDE, F., Derecho penal. Parte especial, Tirant lo Blanch, Valencia, 2010 ${ }^{18}$, p. 593; QUERALT JIMÉNEZ, J .J., Derecho penal español. Parte especial, Atelier, Barcelona, 2008, , p. 869 (citando jurisprudencia al respecto); SILVA SÁNCHEZ, Delitos cit., p. 29; VERCHER NOGUERA, "Responsabilidad penal ambiental” cit., p. 39.
} 
describe de forma alternativa, por lo que si se causan varios resultados (v.gr. emisiones de gases a la atmósfera y vertidos a las aguas, o distintos vertidos) estaremos ante un único delito ${ }^{16}$. De un examen de la jurisprudencia puede advertirse que la gran mayoría de las resoluciones judiciales se refiere a emisiones de sustancias contaminantes a la atmósfera, a los ríos y lagos y asimismo al subsuelo, generalmente procedentes de actividades industriales o también $\operatorname{agrí} \operatorname{colas}^{17}$, si bien destacan asimismo las resoluciones judiciales relativas a supuestos de contaminación acústica ${ }^{18}$.

\subsection{La contravención de las disposiciones protectoras del medio ambiente}

Tal y como se ha expuesto, junto a la conducta de contaminación se exige como primer requisito adicional que el concreto acto contaminante contravenga las leyes $\mathrm{u}$ otras disposiciones generales protectoras del medio ambiente; estamos por consiguiente ante una norma penal en blanco ${ }^{19}$. El artículo 325 se remite a cualquier ley o disposición

\footnotetext{
${ }^{16}$ Cfr. MARTÍNEZ-BUJÁN PÉREZ, Derecho penal económico cit., p. 798.

${ }^{17}$ Ya lo ponía así de relieve CORCOY BIDASOLO, "Protección penal” cit., p. 621, refiriéndose a la jurisprudencia del Tribunal Supremo, y advirtiendo del conjunto de casos "bagatela" que son resueltos por los Tribunales españoles.
}

${ }^{18}$ Vid. sobre este tema GRANADOS PÉREZ, C., "La contaminación acústica como modalidad de delito contra el medio ambiente", López Barja de Quiroga, J. / Zugaldía Espinar, J.M. (coord.), Dogmática y ley penal. Libro Homenaje a Enrique Bacigalupo, Marcial Pons, Madrid, 2004, Tomo II, pp. 969 ss; MARTOS NÚÑEZ, J.A., El delito de contaminación acústica, Iustel, Madrid, 2010, pássim; VERCHER NOGUERA, "Responsabilidad penal ambiental" cit., pp. 41-43. En estas situaciones, lo que sin duda resultará más complicado es demostrar que el elevado nivel de ruidos supone un riesgo para el medio ambiente o para la salud de las personas. Así, mientras que existen algunas sentencias condenatorias en materia de contaminación acústica, que entienden esencialmente que la exposición a determinados niveles de ruido supone un peligro para la salud personal (v.gr. SSAP Barcelona 20-3-2006 (ARP 2006 \194), 2-12009 (ARP 2009\310) y 18-11-2008 (ARP 2009\167), confirmada por la STS 16-11-2009 (RJ 2009\1846); vid. también las sentencias condenatorias del Tribunal Supremo de 5-11-2009 (RJ 2010\301) y 16-6-2009 (RJ 2009\6645)), otras resoluciones judiciales decretan un archivo o una absolución ante la imposibilidad de demostrar la afectación al bien jurídico protegido (v.gr. AAP Toledo 12-6-2008 (ARP 2008\529) y AAP Pontevedra 14-4-2009 (JUR 2009\219811)). Vid. por ej. la jurisprudencia citada en QUERALT JIMÉNEZ, Derecho penal cit., p. 871.

${ }^{19}$ Vid. los requisitos necesarios para la admisibilidad de esta especial técnica normativa, atendiendo a las disposiciones del Tribunal Constitucional, y en general sobre la configuración del artículo 325 como ley penal en blanco, en MARQUÈS I BANQUÉ, M., “Artículo 325”, Quintero Olivares, G. (dir.), Comentarios al Código Penal español. Tomo II, Aranzadi, Cizur Menor, 2011 ${ }^{6}$, pp. 700 ss. Vid. también BERDUGO GÓMEZ DE LA TORRE, I., "La protección penal del medio ambiente. Algunas cuestiones generales", Muñoz Conde, F., (dir.), Problemas actuales del Derecho penal y de la Criminología. Estudios penales en memoria de la Profesora Dra. María del Mar Díaz Pita, Tirant lo Blanch, Valencia, 2008, pp. 1006-1008; BLANCO LOZANO, El delito ecológico cit., pp. 36 ss; GÓMEZ RIVERO, "El delito ecológico" cit., pp. 71 ss: HUERTA TOCILDO, S., "Principios básicos del Derecho penal y artículo 325 del Código Penal”, Revista penal, núm.8, 2001, pp. 44 ss; DE LA MATA BARRANCO, N., "Configuración como ley penal en blanco de los delitos contra el ambiente", AAVV, Estudios jurídicos en memoria del profesor Dr. D. José Ramón Casabó Ruiz, Universidad de Valencia, 1997, Volumen I, pp. 569 ss; MATELLANES RODRÍGUEZ, Derecho penal cit., pp. 64 ss; MENDO ESTRELLA, El 
general que tenga como finalidad la protección del medio ambiente; puede tratase de leyes o de normas de rango inferior pero siempre que presenten el requisito de generalidad $^{20}$. Debe tenerse en cuenta que esta normativa extrapenal no sólo puede consistir en disposiciones estatales o autonómicas ${ }^{21}$, sino que también existe normativa de la Unión Europea que regula esta materia, y que también pueden integrar una ley penal en blanco ${ }^{22}$.

delito ecológico cit., pp. 81 ss; MORALES PRATS, "La estructura" cit., pp. 478 ss; MUÑOZ CONDE, Derecho penal cit., p. 593; PAREDES CASTAÑÓN, J.M., "Responsabilidad penal y "nuevos riesgos": el caso de los delitos contra el medio ambiente", Actualidad Penal, 1997-1, margs. 223 ss; SERRANO TÁRRAGA, M.D. / SERRANO MAÍLLO, A. / VÁZQUEZ GONZÁLEZ, C., Tutela penal ambiental, Dykinson, Madrid, 2009, pp. 143 ss; SILVA SÁNCHEZ, Delitos cit., pp. 57 ss; TERRADILLOS BASOCO, "Delitos" cit., pp. 44 ss; URRAZA ABAD, J., Delitos contra los recursos naturales y el medio ambiente, La Ley, Madrid, 2001, pp. 154 ss.

${ }^{20}$ Se plantea la duda de qué sucede con las disposiciones provenientes de la Administración local. La doctrina por lo general ha excluido la posibilidad de que puedan integrar este artículo 325, partiendo fundamentalmente de que las Administraciones locales no tienen competencia sobre medio ambiente, según el artículo 149 de la Constitución: vid. así MARTÍNEZ-BUJÁN PÉREZ, Derecho penal económico cit., p. 798; SILVA SÁNCHEZ, Delitos cit., p. 60. De este modo, y así lo pone de manifiesto SILVA SÁNCHEZ, se estaría excluyendo del tipo penal algunos casos como los de contaminación acústica, en los que tienen especial incidencia las ordenanzas municipales sobre ruidos. Algún autor, en cambio, sí reconoce la posibilidad de integrar el artículo 325 con normas locales, siempre que estén dirigidas a la generalidad de los ciudadanos; vid. así DE LA CUESTA ARZAMENDI, "Cuestiones dogmáticas" cit., p. 36. Vid. también la STS 5-11-2009 (RJ 2010\301), que expresamente admite la posibilidad de integrar el artículo 325 con ordenanzas municipales, y con base en ello se dicta una condena en un caso de contaminación acústica.

${ }^{21}$ La integración de la norma penal en blanco mediante normativa de las Comunidades Autónomas ha generado diversas objeciones, destacadamente porque puede determinar que una misma conducta resulte típica en una Comunidad Autónoma concreta, y atípica en otra Comunidad diferente; nuestro Tribunal Constitucional (v.gr. STC 120/1998) admite tal posibilidad considerando que las particularidades de cada territorio pueden permitir una regulación diversa en materia medioambiental, lo cual finalmente provocará que la normativa administrativa que integre el artículo 325 sea diferente en las distintas Comunidades Autónomas. Vid. al respecto sobre esta polémica, y sobre las manifestaciones del Tribunal Constitucional, CORCOY BIDASOLO, "Protección penal" cit., pp. 608-609, y bibliografía citada; vid. también BLANCO LOZANO, C., La tutela del agua a través del Derecho penal, Bosch, Barcelona, 2000, pp. 399-400; COLÁS TURÉGANO, "Algunas consideraciones" cit., pp. 425-427; DE LA CUESTA ARZAMENDI, "Cuestiones dogmáticas" cit., p. 36; HUERTA TOCILDO, "Principios básicos" cit., pp. 50-51; DE LA MATA BARRANCO, N., "Delitos contra el medio ambiente: accesoriedad administrativa", AAVV, Técnicas de investigación e infracciones medioambientales, CGPJ, Madrid, 2006, pp. 32 ss; MATELLANES RODRÍGUEZ, Derecho penal cit., pp. 94 ss; MATEOS RODRÍGUEZ-ARIAS, A., Los delitos relativos a la protección del medio ambiente, Colex, Madrid, 1998, pp. 84-85; SOSPEDRA NAVAS, "De los delitos" cit., pp. 176-178; VERCHER NOGUERA, "Responsabilidad penal ambiental" cit., pp. 51-52.

${ }^{22}$ Esta situación puede plantear determinados problemas, sobre todo por la especial naturaleza de algunas normas comunitarias. Así, las Directivas establecen obligaciones para los Estados miembros, que deben ser cumplidas en un determinado plazo. No hay duda de que encajarán en el artículo 325 las Directivas integradas en plazo en el ordenamiento interno; en cambio, en relación con las Directivas que no han sido incorporadas al ordenamiento jurídico estatal en el plazo estipulado, o que han sido incorporadas de forma incorrecta, el propio Tribunal de Justicia de la Unión Europea ha declarado que no cabe fundamentar la responsabilidad penal de un ciudadano con base en estas disposiciones que no han sido objeto de trasposición debida por parte del legislador estatal; vid. sobre esto BAUCELLS LLADÓS, J., Nuevas perspectivas de la política criminal europea en materia ambiental, Atelier, Barcelona, 2007, pp. 
El empleo de esta técnica de reenvío puede plantear diversos problemas a la hora de aplicar el tipo penal; destacadamente, a continuación se tratará qué sucede en los casos en que la única vulneración de la normativa administrativa consiste en la no obtención de la autorización ambiental preceptiva; qué ocurre cuando la autorización administrativa obtenida vulnera la legalidad vigente, y cómo se tratan los supuestos de error sobre la normativa extrapenal protectora del medio ambiente.

En relación con el primer problema planteado, un sector doctrinal entiende que la no obtención de una autorización administrativa obligatoria en materia medioambiental supone una contravención de las normas protectoras del medio ambiente ${ }^{23}$. En cambio, otro sector entiende que aquí no se verifica el tipo básico del delito ecológico; ello se fundamenta en que en tal situación no se afecta el bien jurídico medio ambiente, y sólo se estaría castigando una mera desobediencia administrativa, y en que existe un tipo agravado referido específicamente a la ausencia de autorización administrativa de la concreta actividad. Efectivamente, el artículo 326 CP contiene una circunstancia de agravación del delito ecológico, para los casos de "clandestinidad de la industria o actividad, por ausencia de la preceptiva autorización o aprobación administrativa". Estamos, por lo tanto, ante una "accesoriedad normativa" al ordenamiento administrativo, ya que se exige la contravención de normativa protectora del medio ambiente; no se trata aquí de una "accesoriedad al acto administrativo", que supondría

35-37 y 47 ss; CORCOY BIDASOLO, "Protección penal" cit., pp. 606-607; MATELLANES RODRÍGUEZ, Derecho penal cit., pp. 107-108. Los Reglamentos comunitarios pueden integrar sin ningún problema esta norma penal en blanco; vid. BAUCELLS LLADÓS, Nuevas perspectivas cit., p. 47; CORCOY BIDASOLO, "Protección penal" cit., p. 607; MATELLANES RODRÍGUEZ, Derecho penal cit., pp. 105-106.

Vid. las distintas situaciones que se pueden plantear al integrar una norma penal en blanco por medio de Directivas, extensamente, en MARQUĖS I BANQUÉ, “Artículo 325” cit., pp. 706 ss.

${ }^{23}$ Esta teoría la mantienen, por ejemplo, resoluciones judiciales como la STS 29-9-2001 (RJ 2001\8515), la STS 3-12-2002 (RJ 2003\294) y la SAP Madrid 16-2-2001 (ARP 2001\328).

Vid. DE LA CUESTA ARZAMENDI, "Cuestiones dogmáticas" cit., p. 38; DE LA MATA BARRANCO, Protección penal del ambiente y accesoriedad administrativa, Cedecs, Barcelona, 1996, pp. 107 ss.

DE LA CUESTA ARZAMENDI considera que hubiera sido preferible excluir tales situaciones del ámbito típico, y ello se hubiera logrado si, como en los delitos contra la ordenación del territorio, se incriminaran expresamente las actividades "no autorizables" conforme a la legislación medioambiental. Ello excluiría del tipo aquellas actividades que, si bien no cuentan con la preceptiva autorización administrativa, sí podrían ser autorizables porque cumplen todos los requisitos legales para su concesión. Por su parte, GÓMEZ RIVERO, "El delito ecológico" cit., pp. 79-80, estima que, si bien la mera ausencia de autorización ambiental supone ya una contravención de las normas protectoras del medio ambiente, y por lo tanto encaja en el artículo 325, su incriminación efectiva supondría un olvido de la necesaria antijuridicidad material que debe tener el comportamiento delictivo. 
la incorporación a la redacción típica de la exigencia de un acto administrativo singular (la presencia de una autorización ambiental), convirtiendo la desobediencia a este acto en presupuesto del tipo delictivo ${ }^{24}$.

El segundo problema citado se refiere a los casos en que el sujeto actúa amparado por una autorización administrativa, pero tal acto de la Administración vulnera las disposiciones protectoras del medio ambiente. Evidentemente, al tratarse de una autorización irregular, que a pesar de haber sido concedida por la Administración vulnera la normativa medioambiental, se está verificando el tipo del artículo 325. Además, el sujeto que actúa amparado por esta autorización ilegal ni siquiera podría alegar que su conducta está amparada por una causa de justificación, concretamente la de ejercicio legítimo de un derecho (artículo 20.7), ya que no cabe considerar que sea "legítimo" el derecho concedido por un acto administrativo que vulnera la ley ${ }^{25}$. Únicamente cabría admitir en estos casos la presencia de un error en el sujeto si, como consecuencia de la existencia de la autorización administrativa, cree que su conducta es lícita $^{26}$. Cabe defender que aquí estamos ante un error de tipo, ya que la concesión de la autorización administrativa puede llevar al sujeto a creer que no infringe la normativa protectora del medio ambiente, por lo tanto yerra sobre el elemento típico de "vulneración de las normas medioambientales"27. No obstante, algún sector doctrinal afirma que se trata de un error de prohibición, considerando que la presencia de la

\footnotetext{
${ }^{24}$ Esta es la opinión, por ejemplo, de la STS 26-6-2002 (RJ 2002\7214) y de la SAP León 17-2-1997 (ARP 1997\366). Vid. las razones a favor de esta postura en MARQUÈS I BANQUÉ, "Artículo 325" cit., pp. 703 ss. Vid. también las consideraciones de GÓMEZ RIVERO, “El delito ecológico” cit., pp. 79-80.

${ }^{25}$ Vid. sobre este tema GÓMEZ RIVERO, M.C., El régimen de autorizaciones en los delitos relativos a la protección del medio ambiente y ordenación del territorio, Tirant lo Blanch, Valencia, 2000, pp. $50 \mathrm{ss;}$ MATELLANES RODRÍGUEZ, Derecho penal cit., p. 126; MARQUÈS I BANQUÉ, "Artículo 325" cit., pp. 725-726; SILVA SÁNCHEZ, Delitos cit., p. 69. Merece destacarse que se ha puesto de relieve la posibilidad de apreciar la eximente cuando la autorización irregular no es nula, sino meramente anulable, de tal forma que ante vicios de escasa gravedad que no determinen la nulidad del acto de la Administración podría admitirse su eficacia a los solos efectos de apreciar la exención de responsabilidad penal; vid. GÓMEZ RIVERO, "El delito ecológico" cit., p. 79.

${ }^{26}$ El error podría ser vencible ( $s i$ el sujeto, en función de sus capacidades, podría haberlo evitado) o invencible. Afirma SILVA SÁNCHEZ, Delitos cit., pp. 94-95, que generalmente cabrá calificar este error como invencible, considerando que no puede exigirse al ciudadano que verifique la legalidad del acto administrativo de autorización. Cfr. también CORCOY BIDASOLO, "Protección penal" cit., pp. 645646.

27 Vid. BAUCELLS LLADÓS, "De los delitos" cit., p. 1396; DE LA CUESTA ARZAMENDI, “Cuestiones dogmáticas" cit., p. 38; GÓMEZ RIVERO, El régimen cit., p. 50, y "El delito ecológico" cit., p. 78; MENDO ESTRELLA, El delito ecológico cit., pp. 152-153; SILVA SÁNCHEZ, Delitos cit., p. 93.
} 
autorización ambiental irregular determina que el sujeto no sea consciente de la antijuridicidad de su comportamiento ${ }^{28}$.

El tercer problema planteado se refiere a cómo tratar los casos de error sobre la normativa medioambiental a la cual remite el artículo 325. Este supuesto puede ser bastante frecuente, teniendo en cuenta la gran proliferación normativa en este ámbito y las posibles dificultades para conocer todas las regulaciones existentes. Aquí podemos diferenciar dos supuestos en función de cuál es el objeto concreto del error: el error sobre los presupuestos de hecho de la norma infringida, y el error sobre el alcance de la propia norma extrapenal.

El error sobre los presupuestos de hecho de la norma infringida se refiere a aquellos casos en que el sujeto ignora que su actividad es contaminante, es decir, no es consciente de que está llevando a cabo comportamientos que vulneran las disposiciones protectoras del medio ambiente. Así, por ejemplo, ello ocurriría cuando el sujeto realiza vertidos contaminantes desconociendo el grado de concentración de sustancias tóxicas en tales vertidos; por consiguiente, al faltarle este dato, no puede saber si está vulnerando alguna normativa medioambiental. Nos encontramos aquí ante un error de tipo, ya que se yerra sobre la concurrencia de uno de los elementos del tipo penal: la infracción de la normativa extrapenal protectora del medio ambiente ${ }^{29}$.

El error sobre el alcance de la norma extrapenal significa que el sujeto conoce todas las características de su actividad, pero no sabe que se encuentra sancionada por la normativa medioambiental; esto es, el sujeto lleva a cabo un vertido, conociendo el grado de concentración de sustancias tóxicas, pero no sabe que ese tipo de vertidos está prohibido por la ley. Algunos autores consideran que estamos aquí ante un error de prohibición, ya que se trata de un desconocimiento de la normativa, no de un elemento típico; sin embargo, realmente puede afirmarse que sí estamos ante un error de tipo, puesto que el sujeto yerra sobre uno de los elementos constitutivos del tipo: estar contraviniendo la normativa protectora del medio ambiente ${ }^{30}$.

\footnotetext{
${ }^{28}$ Vid. de esta opinión MATELLANES RODRÍGUEZ, Derecho penal cit., pp. 124-126. Vid. sobre este tema MARQUĖS I BANQUÉ, “Artículo 325” cit., pp. 726-727.

${ }^{29}$ Vid. sobre esto SILVA SÁNCHEZ, Delitos cit., p. 90.

${ }^{30}$ Vid. DE LA CUESTA ARZAMENDI, "Cuestiones dogmáticas” cit., p. 38; SILVA SÁNCHEZ, Delitos cit., pp. 90-91.
} 
La admisión de ambos tipos de errores como errores de tipo tiene consecuencias prácticas importantes, ya que bloquea la punición de los partícipes: efectivamente, si el error es invencible, el hecho queda impune por ausencia de un elemento del tipo, y el principio de accesoriedad limitada de la participación impide castigar a los partícipes; y por otra parte, si el error es vencible, el hecho se castiga como imprudente, y resulta muy discutida la admisibilidad de la participación en los delitos imprudentes ${ }^{31}$.

\subsection{La posibilidad de perjudicar gravemente el equilibrio de los sistemas naturales}

El segundo elemento adicional exigido al acto de contaminación, a mayores de la vulneración de la normativa medioambiental, consiste en que tal acto pueda perjudicar gravemente el equilibrio de los sistemas naturales. Se configura así un delito de peligro hipotético o delito de aptitud, castigando una acción apta o idónea para producir un peligro para el bien jurídico protegido (el medio ambiente) ${ }^{32}$. Aquí el legislador no se limita a describir una acción generalmente peligrosa, pero tampoco llega a exigir la concurrencia de un resultado de peligro concreto para el bien jurídico; habrá que demostrar la peligrosidad de la acción y la posibilidad del resultado de peligro. A esto no ayuda el hecho de que el objeto puesto en peligro aparece definido de forma absolutamente indeterminada: "equilibrio de los sistemas naturales", ni tampoco el hecho de que en la mayoría de los atentados medioambientales la conducta desarrollada implica ya daños para determinados elementos del ecosistema. Habría que acreditar la idoneidad del acto de contaminación para poner en peligro el equilibrio de los sistemas naturales en un determinado contexto fáctico, esto es, hacer una hipótesis sobre si es

\footnotetext{
${ }^{31}$ Vid. SILVA SÁNCHEZ, Delitos cit., pp. 90 ss.

${ }^{32}$ Vid. por ejemplo ALASTUEY DOBÓN, El delito cit., pp. 107-108; MARTÍNEZ-BUJÁN PÉREZ, Derecho penal económico cit., p. 798; MUÑOZ CONDE, Derecho penal cit., p. 593. Vid. también COLÁS TURÉGANO, "Algunas consideraciones" cit., pp. 439-440; DE LA CUESTA ARZAMENDI, "Cuestiones dogmáticas" cit., p. 33; GARCÍA RIVAS, Delito ecológico cit., p. 136; GÓMEZ RIVERO, "El delito ecológico" cit., p. 81; MARQUÈS I BANQUÉ, "Artículo 325" cit., p. 723; MENDO ESTRELLA, El delito ecológico cit., p. 128; MENDOZA BUERGO, B., "El delito ecológico: configuración típica, estructuras y modelos de tipificación”, Jorge Barreiro, A. (dir.), Estudios sobre la protección penal del medio ambiente en el ordenamiento jurídico español, Comares, Granada, 2005, p. 117; MORALES PRATS, "La estructura" cit., p. 497; MUÑOZ LORENTE, J., "Algunas consideraciones sobre los delitos contra el medio ambiente en la jurisprudencia del Tribunal Supremo", Revista del Poder Judicial, núm. 67, 2002, pp. 168 ss. Se decantan por el peligro abstracto CORCOY BIDASOLO, "Protección penal" cit., p. 631; VERCHER NOGUERA, "Responsabilidad penal ambiental" cit., p. 28. Hablan de peligro concreto BOIX REIG / JAREÑO LEAL, "De los delitos" cit., p. 1598; BLANCO LOZANO, El delito ecológico cit., p. 55.
} 
posible que la conducta y el resultado producidos lleguen a causar una lesión al medio ambiente ${ }^{33}$.

La calificación de este delito en la jurisprudencia es sumamente confusa, y así encontramos resoluciones que lo califican como de peligro concreto, otras de peligro abstracto, y finalmente otras de peligro hipotético ${ }^{34}$. De forma mayoritaria, los jueces y tribunales han tendido a calificar el delito del artículo 325 como de peligro concreto, siguiendo la inercia interpretativa del artículo 347 bis del Código penal de 1944/1973 ${ }^{35}$; no obstante, otras resoluciones califican el peligro como abstracto ${ }^{36}$, y con el paso del tiempo se ha venido calificando cada vez más como de peligro hipotético ${ }^{37}$.

Debe tenerse en cuenta que, en muchas ocasiones, el resultado de la acción contaminante será la efectiva muerte de especies animales o vegetales o la causación de cualquier otro tipo de daños efectivos a elementos del medio ambiente. En todo caso, conviene realizar aquí una advertencia: no es necesario demostrar, como a veces han pretendido los jueces y tribunales para imponer una condena por delito ecológico, una

33 Como manifiesta SILVA SÁNCHEZ, Delitos cit., p. 25, debe establecerse en primer lugar "una relación de causalidad entre la conducta de que se trate y el resultado físico - natural del vertido, emisión, aterramiento, ruido, etc.", y en segundo lugar, "el juicio normativo de imputación a dicho resultado físiconatural del peligro grave para el equilibrio de los ecosistemas" (vid. también pp. 44 ss.). Vid. también en esta línea CORCOY BIDASOLO, M. / VIVES-REGO, J., "La evaluación del riesgo y del impacto (o daño) en el delito ecológico: aspectos jurídicos y forenses", Revista del Poder Judicial, núm. 83, 2006, p. 114, distinguiendo la necesidad de probar, en primer lugar, la citada relación de causalidad, y en un momento posterior la relación de riesgo para el bien jurídico medio ambiente.

34 Manifiesta MUÑOZ LORENTE, J., "El cambio de criterio jurisprudencial en relación con la calificación del peligro exigido para la consumación del tipo básico de los delitos contra el medio ambiente: el artículo 325 del Código Penal y su estructura de peligro hipotético" (I), Revista interdisciplinar de Gestión Ambiental, núm. 54, 2003, pp. 70 ss, que en ocasiones el Tribunal Supremo ha calificado el delito ecológico como de peligro abstracto, pero que al interpretarlo maneja criterios propios del peligro hipotético; incluso, este autor afirma que, aun siendo calificado como de peligro concreto, el TS ha interpretado tradicionalmente esta figura delictiva como si fuera un delito de peligro hipotético. Vid. en esta línea también MATELLANES RODRÍGUEZ, Derecho penal cit., pp. 115 ss. Asimismo manifiesta DE LA MATA BARRANCO, "Protección penal del ambiente" cit., p. 240, que en numerosas ocasiones los tribunales, aun calificando este delito como de peligro concreto, se conforman con constatar la existencia de un peligro posible o potencial para el equilibrio de los sistemas naturales.

${ }^{35}$ V.gr. SSAP Barcelona 23-1-2002 (ARP 2002\216) y 22-2-2000 (ARP 2000\10). Vid. una recopilación de sentencias relativas a los delitos contra el medio ambiente dictadas bajo la vigencia del anterior Código penal, en MATEOS RODRÍGUEZ -ARIAS, Los delitos cit., pp. 73 ss. Vid. también RODRÍGUEZ LÓPEZ, Medio ambiente cit., pp. 291 ss.

\footnotetext{
${ }^{36}$ V.gr. STS 22-7-2004 (RJ 2004\7294); SAP Barcelona 6-10-2003 (JUR 2003\258866).

${ }^{37}$ V.gr. SSTS 19-4-2010 (RJ 2010\5043), 8-4-2008 (RJ 2008\1852), 1-4-2003 (RJ 2003\4062), 20-122007 (RJ 2008\1315) y 17-5-2003 (RJ 2003\4240).
} 
relación directa entre el vertido y, por ej., la muerte de especies de la flora o fauna ${ }^{38}$. Efectivamente, sólo será necesario probar la relación de causalidad entre la acción y el concreto resultado producido (v.gr. que los vertidos de sustancias tóxicas en un río proceden de la actividad de eliminación de residuos de una fábrica adyacente), y a continuación demostrar que este hecho resulta potencialmente peligroso para el medio ambiente $^{39}$. Ha de verificarse alguna de las situaciones (modificaciones del sistema natural) descritas en el tipo, ya sean vertidos, aterramientos, emisiones, etc.; esto sólo quiere decir que han de constatarse, respectivamente, la presencia de desechos en el mar, el desplazamiento de tierras, o la existencia de gases contaminantes en la atmósfera, pero el tipo no exige la producción de muertes o daños a las especies de flora o fauna, a las aguas, etc. Lo único que habrá que constatar es que tal concreto vertido, aterramiento, emisión, etc., presenta idoneidad para causar un grave perjuicio al equilibro de los sistemas naturales, o en una expresión más plástica, idoneidad para producir precisamente una grave alteración del ecosistema que generalmente consistirá en la muerte de especies vivas o en la alteración de aguas, aire, etc. Frecuentemente la verificación de tales muertes o daños en los elementos naturales son la prueba irrefutable de que el resultado físico-natural (vertido, emisión, etc.) era apto para causar un grave perjuicio, pero no es necesario que se produzcan efectivamente tales daños sino que únicamente es preciso demostrar la aptitud de tal resultado para causarlos ${ }^{40}$.

\footnotetext{
${ }^{38}$ Vid. MENDOZA BUERGO, "El delito ecológico" cit., pp. 136-138, citando las manifestaciones en este sentido contenidas en las SSTC 127/1990, de 5 de julio, y 42/1999, de 22 de marzo. Vid. también GÓMEZ RIVERO, "El delito ecológico" cit., p. 82.

Vid. también DE LA CUESTA AGUADO, Causalidad cit., pp. 249-250; de la misma autora, La prueba en el delito ecológico, Tecnos, Madrid, 1995, pp. 19-20; HORMAZÁBAL MALAREE, "El principio de lesividad" cit., p. 1426; MUÑOZ CONDE, Derecho penal cit., p. 594.

${ }^{39}$ Como manifiesta DE LA MATA BARRANCO, "Protección penal del ambiente" cit., p. 239, en ocasiones los tribunales confunden la comprobación de la relación de causalidad entre la conducta y el resultado de contaminación producido, con la demostración del nexo entre este resultado (la contaminación) y la posibilidad de un peligro grave para el medio ambiente. Por ello, como con razón afirman CORCOY BIDASOLO / VIVES-REGO, "La evaluación" cit., p. 104, los informes periciales deben separar las conclusiones y valoraciones sobre los daños causados de las consideraciones dirigidas a precisar los riesgos derivados de los procesos contaminantes.
}

${ }^{40}$ Vid. PUENTE ABA, L.M., "La represión penal de vertidos marinos intencionados: cuestiones relativas al riesgo de contaminación y a la atribución de responsabilidades", Meilán Gil, J.L. (dir.), Estudios sobre el régimen jurídico de los vertidos de buques en el medio marino, Aranzadi, Cizur Menor, 2006, pp. 566-567.

Debe ponerse de relieve que el Tribunal Constitucional ha declarado que el delito medioambiental "no requiere acreditar la relación causal entre el vertido y la muerte concreta de especies piscícolas, sino tan sólo que se produzca un peligro grave para las condiciones de la vida animal. Es indiferente, por tanto, que esté acreditado o no que determinadas aves o peces murieran precisamente como consecuencia de un 
Partiendo de que el delito ecológico es un delito de peligro hipotético, habrá que determinar qué criterios emplean los jueces y tribunales para dar por verificada la existencia de esa aptitud o idoneidad para perjudicar el medio ambiente.

Puede aceptarse la idea de que un vertido sería apto para causar grave daño al equilibrio de un sistema natural cuando existe una ley científica según la cual es posible reconocer una relación causa-efecto entre el concreto vertido y determinados daños naturales; se ha dicho que no bastaría, en ningún caso, una mera probabilidad estadística, es decir, si un vertido no ha producido daños efectivos sólo se podría decir que es apto para causarlos cuando según una ley científica está demostrado que puede provocarlos, pero no bastaría que estadísticamente, y sin base en la ciencia, sea frecuente que de tal vertido deriven determinados daños medioambientales ${ }^{41}$. Por el contrario, hay otra teoría según la cual, ante la imposibilidad de que exista una ley científica que explique todos los posibles procesos causales en la Naturaleza, debería ser válida una ley puramente estadística; se admitiría entonces que un vertido es apto para causar daños al medio ambiente cuando se ha constatado empíricamente que un determinado evento (v.gr. una específica forma de vertido) conduce casi siempre a un mismo resultado (v.gr.

concreto vertido cuando consta que con independencia de ello el vertido en sí mismo es gravemente perjudicial para las condiciones de la vida animal" (STC 127/1990, de 5 de julio).

También la STS 8-11-2004 (RJ 2004\7711) ha señalado que "el tipo penal, como tipo de peligro, no requiere la comprobación de la causalidad del daño, sino el carácter peligroso del vertido... Lo único que se requiere es establecer si el vertido tiene la aptitud para generar tales peligros". Asimismo, según la SJP de León 31-3-2003 (ARP 2003\344), es indiferente acreditar la relación causal entre el vertido y la muerte concreta de especies piscícolas cuando consta que el vertido es en sí mismo gravemente perjudicial para las condiciones de vida animal. Por último, la SAP Vizcaya de 28-8-2001 (JUR 2002\3043), establece que no sería necesaria, para dictar sentencia condenatoria, la producción de la muerte de los peces, siendo suficiente con unos informes periciales que determinan que la concentración de hierro y cromo, superior a la establecida reglamentariamente, es altamente contaminante y letal para la vida acuática.

${ }^{41}$ Vid. al respecto ALASTUEY DOBÓN, El delito cit., p. 125. También destaca la utilidad de este criterio, mencionando que no obstante no resulta útil para resolver todos los casos que se pueden plantear, DE LA CUESTA AGUADO, Causalidad cit., pp. 265-266; la misma autora, La prueba cit., pp. 17-19. Habla también SILVA SÁNCHEZ, Delitos cit., p. 77, de la necesidad de tener en cuenta las leyes de la experiencia.

Una muestra del empleo de las leyes científicas la hallamos, por ej., en la SAP Barcelona 6-10-2003 (JUR $2003 \backslash 258866$ ), que se apoya en un informe del Instituto Nacional de Toxicología, según el cual "la elevada demanda química de oxígeno del vertido provoca que el oxígeno disuelto en el río descienda de forma considerable, y la demanda química de oxígeno aguas abajo situada en $120 \mathrm{mg} / \mathrm{l}$ determina que el río se convierta en un ecosistema forzado de depuración con ambiente anóxico en el fondo del río. Asimismo la concentración de aceites y grasas puede dar lugar a la formación de una película superficial que impide el intercambio de oxígeno y otros gases con la atmósfera incrementando de esta forma el déficit de oxígeno en el agua". Vid. también la STS 25-10-2002 (RJ 2002\10461), que atiende a la composición química de la sustancia vertida. Vid. asimismo la STS 30-12-2008 (RJ 2009\1380), de carácter absolutorio por no encontrar base científica suficiente para afirmar la gravedad del peligro para el medio ambiente. 
la producción de determinados daños medioambientales), aunque no exista una teoría científica que explique satisfactoriamente el curso causal desarrollado ${ }^{42}$. En fin, recapitulando las claves definitorias de este requisito de aptitud en el delito ecológico, se ha dicho que es necesario conjugar tres variables: una cualitativa, que atenderá a las propiedades del elemento contaminante; otra cuantitativa, valorando la intensidad con que se ha realizado la acción; y una última temporal, atendiendo a la duración de la acción o de sus efectos ${ }^{43}$. Como conclusión, puede afirmarse que al fin y al cabo este requisito típico presenta un carácter valorativo, y su verificación dependerá del análisis del caso concreto con la ayuda de los criterios que se acaban de exponer ${ }^{44}$.

Analizando lo que dice la jurisprudencia en relación con los posibles indicios que demuestren la existencia del requisito de idoneidad, el Tribunal Supremo señala reiteradamente que habrá que examinar en qué medida son puestos en peligro la salud de las personas (factor antropocéntrico) y también las condiciones naturales del ecosistema (suelo, aire, agua, flora, fauna) (v.gr. STS 30-6-2004, RJ 2004\5085; STS 19-4-2010, RJ 2010\5043). Asimismo la STS 25-5-2004 (RJ 2004\4166) establece que debe determinarse "de la forma más precisa posible "las características del vertido" (composición, caudal y duración), "características del medio receptor" (composición antes y después del vertido y el caudal) y "condiciones de vida animal o vegetal en el medio receptor que puedan haberse visto afectadas por el vertido" 45 .

No obstante, no resulta una cuestión pacífica la validez de todos estos indicios de referencia para atestiguar la peligrosidad de un acto contaminante; a título de ejemplo, y en relación con las "características del medio receptor" que se acaban de señalar, es interesante señalar los supuestos de vertidos en aguas fluviales que son calificadas como "río muerto". A uno de tales casos se refiere la STC 42/1999, de 22 de marzo, que

\footnotetext{
${ }^{42}$ Así lo expone DE LA CUESTA AGUADO, Causalidad cit., pp. 267-269; de la misma autora, La prueba cit., pp. 17-19.

VAELLO ESQUERDO, "Los delitos" cit., p. 28, pone de relieve que el Tribunal Supremo suele considerar que no es necesario el recurso a pruebas estrictamente científicas, sino que bastaría, para probar la relación causal, la certidumbre subjetiva del tribunal fundamentada en leyes estadísticas o en la simple constatación de que la conducta realizada supone una alta probabilidad de causar un riesgo grave para el sistema natural.

${ }^{43}$ Vid. DE LA CUESTA AGUADO, Causalidad cit., p. 239.

${ }^{44}$ Vid. PUENTE ABA, “La represión penal” cit., pp. 568-569.

${ }^{45}$ Vid. recopilando estos criterios manejados por la jurisprudencia, DE LA MATA BARRANCO, "Protección penal del ambiente" cit., pp. 241-242.
} 
deniega el amparo solicitado por un sujeto condenado por comisión de un delito ecológico por la SAP de Barcelona de 16-2-1996, que revocaba la absolución decretada por la Sentencia del Juzgado de lo Penal núm. 2 de Sabadell de 21-7-1995; según el Tribunal Constitucional, el juicio sobre la peligrosidad de un vertido contaminante no ha de hacerse depender del lugar donde se realiza, sino de sus propias características, esto es, de si presenta elementos que pueden poner en grave riesgo el mantenimiento de la vida vegetal y animal ${ }^{46}$; esta es la opinión también, por ejemplo, de las SSTS 22-72004 (RJ 2004\7294) y 8-11-2004 (RJ 2004\7711) ${ }^{47}$.

Finalmente, queda por tratar una cuestión en el análisis de este requisito de aptitud: se exige la idoneidad para perjudicar "gravemente" el equilibrio de los sistemas naturales. Si ya de por sí resulta difícil establecer unos contornos precisos del contenido del requisito de peligro hipotético, más complicado resulta aún determinar cuándo tal peligro se refiere a la producción de un daño "grave". La intención del legislador es sin duda excluir del tipo aquellas conductas que suponen únicamente un riesgo de producción de un perjuicio mínimo para el medio ambiente; el problema surge, no

\footnotetext{
${ }^{46}$ La sentencia dice textualmente que "las concentraciones de metales y la demanda química de oxígeno de los fluidos vertidos "son absolutamente incompatibles con la vida animal macroscópica propia de los ríos de la zona". Predicar de esta absoluta incompatibilidad con la vida animal, la posibilidad, exigida en el tipo, de ocasionar un perjuicio grave a las condiciones en que la vida animal puede desarrollarse, no puede ser tildada de extravagante... Esta calificación no se torna contraria al canon de previsibilidad y razonabilidad antes expuesto por el hecho de que, en el momento de los vertidos, los ríos afectados fueran adjetivados de «ríos muertos», toda vez que, como afirma con razón el Ministerio Fiscal, se trata de una expresión más retórica que técnica, que, como se deduce de las declaraciones de los Peritos efectuadas en el juicio oral, no excluye que un río calificable en un determinado momento como «muerto» no pueda calificarse en ese mismo momento de regenerable, es decir, como capaz de devenir un río con vida animal o vegetal en el futuro y, en consecuencia, un río en el que los vertidos de ciertas sustancias puedan perjudicar gravemente el desarrollo de las condiciones de vida animal".
}

En la doctrina pueden encontrarse opiniones diversas al respecto. HORMAZÁBAL MALAREE, "El principio de lesividad" cit., p. 1427, considera incorrecto sostener que en estas hipótesis de vertidos a un "río muerto" no se verifica el delito ecológico porque el medio ambiente ya estaba lesionado; según el autor, habría que comprobar si el vertido creó un riesgo mayor para el bien jurídico al aumentar los factores de riesgo y hacer más probable el daño medioambiental; vid. en esta línea asimismo BAUCELLS LLADÓS, "De los delitos" cit., p. 1393; CORCOY BIDASOLO, “Artículo 325" cit., pp. 740-741. Vid. también las consideraciones de CORCOY BIDASOLO / VIVES-REGO, "La evaluación" cit., p. 114; SILVA SÁNCHEZ, Delitos cit., pp. 78 ss; TERRADILlOS BASOCO, J.M., "Artículo 325 del Código penal. Lecturas jurisprudenciales", AAVV, Técnicas de investigación e infracciones medioambientales, CGPJ, Madrid, 2006, pp. 146-147; VERCHER NOGUERA, A., "Reflexión sobre las emisiones y vertidos en los delitos contra el medio ambiente y algunos aspectos determinantes en los mismos", Revista penal, núm.7, 2001, pp. 99 ss; del mismo autor, "Responsabilidad penal ambiental" cit., pp. 4041.

${ }^{47}$ Dice el Tribunal Supremo que "lo único que se requiere es establecer si el vertido tiene la aptitud para generar tales peligros y la tipicidad será de apreciar inclusive cuando el vertido pueda caer sobre zonas ya contaminadas, dado que la finalidad del tipo penal no es sólo evitar contaminación, sino también impedir el incremento de la ya existente, pues esto contribuiría a dificultar la reparación del daño ya causado". 
obstante, a la hora de determinar cuándo un determinado daño (que además no tiene por qué producirse, sólo se exige el riesgo de que se verifique) es grave o leve. Inevitablemente nos movemos en el ámbito de conceptos valorativos, y será tarea del juez en cada caso concreto determinar cuándo ha habido riesgo de producción de un perjuicio grave para el ambiente natural. De todos modos, para reconocer la gravedad del daño que amenaza con producirse, puede atenderse a la presencia de indicadores como los siguientes: evidencia de altas probabilidades de producción de la lesión; y magnitud de la lesión previsible en función de la extensión del espacio afectado, de la prolongación en el tiempo del vertido, de la intensidad de la afectación del mar, la concentración y cantidad de la sustancia contaminante vertida, de las características de las aguas receptoras, etc ${ }^{48}$. Tales parámetros, además, con frecuencia habrán de quedar establecidos en los informes periciales, y los jueces y tribunales habrán de decidir, ayudándose de estos criterios científicos, si la actividad contaminante en cuestión podía provocar un peligro grave para el medio ambiente ${ }^{49}$.

\footnotetext{
${ }^{48}$ Vid. estos parámetros en SILVA SÁNCHEZ, Delitos cit., p. 79, y en la STS 30-12-2008 (RJ 2009\1380), STS 30-6-2004 (RJ 2004\5085), la SJP León 31-3-2003 (ARP 2003\344) y la SAP Tarragona 24-5-2001 (ARP 2001\579); vid. también VAELLO ESQUERDO, "Los delitos" cit., p. 21, citando asimismo jurisprudencia al respecto. Puede verse también MENDO ESTRELLA, El delito ecológico cit., pp. 122-124; QUERALT JIMÉNEZ, Derecho penal cit., pp. 869-870; SERRANO TÁRRAGA / SERRANO MAÍLLO / VÁZQUEZ GONZÁLEZ, Tutela penal ambiental cit., pp. 159-160.
}

${ }^{49}$ Así, por ej., la SAP Baleares 9-6-2008 (ARP 20081506) toma como base que "los peritos citados informaron que, con carácter general, la situación de riesgo para las aguas subterráneas, propiciada por los vertederos, viene definida por cuatro elementos: la mayor o menor pluviometría; la mayor o menor permeabilidad del terreno; la mayor o menor altura de los vertederos en relación a los niveles de las aguas subterráneas; y la existencia o no de captaciones de aguas en el sentido del flujo natural de las mismas". En ese caso concreto no se demostró que se verificaran tales condiciones en relación con las sustancias contaminantes llegadas desde un vertedero a las aguas subterráneas, y por lo tanto, el tribunal consideró que no existía la posibilidad de causar un perjuicio grave al medio ambiente.

Asimismo, cabe citar las manifestaciones de la STS 14-2-2001 (RJ 2001\1240), reproducidas por la STS 30-12-2008 (RJ 2009\1380), de acuerdo con las que "parece seguro referenciar el criterio de la gravedad del perjuicio a la intensidad del acto contaminante, a la probabilidad de que el peligro se concrete en un resultado lesivo, en definitiva, a la magnitud de la lesión en relación con el espacio en el que se desarrolla, la prolongación en el tiempo, la afectación directa o indirecta, la reiteración de la conducta, de los vertidos, emisiones, etc., a la dificultad para el restablecimiento del equilibrio de los sistemas, proximidad de las personas o de elementos de consumo. En todo caso, estos criterios necesitan de una prueba pericial que lo exponga, al menos que el Juez sea asesorado pericialmente por expertos que expongan los criterios anteriormente relacionados y sobre los que se establezca la necesaria contradicción evitando que las percepciones del Juez se conviertan en presupuesto inseguro en la aplicación del tipo penal... La gravedad se ha de deducir, pues, de ambos elementos conjuntamente lo que significa negar la tipicidad en los casos de resultados solo posibles o remotamente probables, así como de aquellos que, de llegar a producirse, afecten de manera insignificante al bien jurídico". En esta misma línea, pueden citarse las SSTS 30-6-2004 (RJ 2004\5085), 30-12-2008 (RJ 2009\1380) y 14-2-2001 (RJ 2001\1240) y las SSAP Baleares 9-6-2008 (ARP 2008\506), Segovia 24-5-2005 (JUR 2005\208074) y Tarragona de 24-52001 (ARP 2001\579). 


\section{El tipo autónomo por el riesgo para la salud de las personas: el inciso $2^{\circ}$ del} artículo 325

En el primer inciso del artículo 325 se sanciona un acto de contaminación que vulnera la normativa protectora del medio ambiente y que es idóneo para perjudicar gravemente el medio ambiente. El siguiente inciso del artículo 325 establece un endurecimiento de la pena prevista (se aplicará la pena del tipo básico, pero en su mitad superior) "si el riesgo de grave perjuicio fuera para la salud de las personas".

Lo que fundamenta la agravación de la pena es, por lo tanto, el alcance del peligro hipotético exigido en el tipo penal: en el inciso $1^{\circ}$ se refiere únicamente a la afectación del equilibrio de los sistemas naturales, y en el inciso $2^{\circ}$ a la salud de las personas. Lo que es necesario discernir es si nos encontramos ante un tipo cualificado ${ }^{50}$, dependiente del tipo básico del inciso $1^{\circ}$, o si nos encontramos ante un tipo formalmente autónomo. Para ser un tipo cualificado, deberían de verificarse todos los elementos del tipo básico del inciso $1^{\mathrm{o}}$, y a mayores la específica circunstancia de agravación; en este caso, la redacción legal parece que no se manifiesta en este sentido, puesto que no se exige que concurra un riesgo para el medio ambiente y además para la salud personal, sino que el texto establece simplemente un marco penal distinto (más agravado) en el caso de que el peligro afecte a la salud de las personas. Por lo tanto, estamos ante un tipo autónomo, en el que se castiga un acto de contaminación que vulnere la normativa medioambiental protectora del medio ambiente, y que sea idóneo para poner en riesgo la salud de las personas, sin necesidad de comprobar el peligro hipotético para algún sistema natural específico $^{51}$.

La elección de una $\mathrm{u}$ otra alternativa posee, realmente, importantes consecuencias prácticas. Considerando, por lo tanto, que los incisos $1^{\circ}$ y $2^{\circ}$ del artículo 325 contienen dos tipos autónomos, sería posible apreciar un concurso de delitos entre ambos en los casos en que el acto de contaminación supone, simultáneamente, un peligro hipotético

\footnotetext{
50 De esta opinión CORCOY BIDASOLO, "Protección penal” cit., pp. 615 y 631-632; GÓMEZ RIVERO, "El delito ecológico" cit., p. 92; MATELLANES RODRÍGUEZ, Derecho penal cit., p. 127; MORALES PRATS, "La estructura” cit., p. 496; URRAZA ABAD, Delitos cit., pp. 250-251.

${ }^{51}$ Vid. BAUCELLS LLADÓS, "De los delitos" cit., p. 1395; CORCOY BIDASOLO, "Artículo 325” cit., p. 742; DE LA CUESTA ARZAMENDI, "Cuestiones dogmáticas" cit., p. 32; MARTÍNEZ-BUJÁN PÉREZ, Derecho penal económico cit., p. 799; DE LA MATA BARRANCO, "Protección penal del ambiente" cit., pp. 229; MENDO ESTRELLA, El delito ecológico cit., p. 131; SILVA SÁNCHEZ, Delitos cit., pp. 96-97; VAELLO ESQUERDO, “Los delitos” cit., pp. 32-33.
} 
para el equilibrio de los sistemas naturales y para la salud de las personas ${ }^{52}$. Asimismo, la consideración del inciso $2^{\circ}$ como un tipo autónomo abre la posibilidad de su comisión por imprudencia ${ }^{53}$; efectivamente, si se entiende que este inciso únicamente configura una circunstancia de agravación de la conducta del inciso $1^{\circ}$, no sería posible admitir la comisión imprudente, ya que el artículo 14.2 excluye la punición de los casos de error sobre circunstancias agravantes y elementos de los tipos cualificados; por consiguiente, la provocación no dolosa de un peligro para la salud personal no podría ser objeto de sanción penal.

\section{EL TIPO SUBJETIVO}

Las dos figuras delictivas incluidas en el artículo 325 son de carácter doloso, y se considera admisible el dolo eventual ${ }^{54}$. Debe tenerse en cuenta que, en virtud del artículo 331, se incrimina también la realización de estas conductas con imprudencia grave.

En el ámbito de esta categoría de delitos es factible encontrar determinados supuestos de error de tipo, excluyentes del dolo, derivados destacadamente de la configuración de las figuras delictivas como normas penales en blanco. Así, podrá apreciarse la presencia de un error de tipo, vencible o invencible, en aquellos casos en que el sujeto yerra sobre la vulneración de la normativa medioambiental, requisito exigido en el artículo 325: puede tratarse de un error sobre los presupuestos de hecho de la norma infringida (el sujeto ignora que su actividad es contaminante), o de un error sobre el alcance de la norma extrapenal (el sujeto conoce todas las características de su actividad, pero no sabe que se encuentra sancionada por la normativa medioambiental). Por último, también es de interés examinar los casos en que el sujeto actúa amparado por una autorización administrativa ilícita, esto es, la propia Administración ha concedido un permiso que infringe la normativa protectora del medio ambiente; en tal caso, habrá que

\footnotetext{
${ }^{52}$ Vid. MENDO ESTRELLA, El delito ecológico cit., p. 185; SILVA SÁNCHEZ, Delitos cit., p. 97; VAELLO ESQUERDO, "Los delitos" cit., pp. 32-33.

${ }^{53}$ Vid. MARTÍNEZ-BUJÁN PÉREZ, Derecho penal económico cit., p. 799; SILVA SÁNCHEZ, Delitos cit., p. 98.

${ }^{54}$ Cfr. ALASTUEY DOBÓN, El delito cit., p. 131; BAUCELLS LLADÓS, "De los delitos" cit., p. 1396; CORCOY BIDASOLO, "Artículo 325" cit., p. 739; GÓMEZ RIVERO, "El delito ecológico" cit., pp. 8889; MARTÍNEZ-BUJÁN PÉREZ, Derecho penal económico cit., p. 798; MATELLANES RODRÍGUEZ, Derecho penal cit., p. 124; MENDO ESTRELLA, El delito ecológico cit., pp. 144 ss; MUÑOZ CONDE, Derecho penal cit., p. 595; QUERALT JIMÉNEZ, Derecho penal cit., p. 874; SILVA SÁNCHEZ, Delitos cit., pp. 88 ss.
} 
determinar la admisibilidad de un error en el sujeto, que puede confiar en no estar vulnerando las normas medioambientales al actuar con el permiso de las propias autoridades. Tales supuestos, que pueden implicar la presencia de errores de tipo vencibles o invencibles, han sido examinados al analizar, en el marco de la conducta típica del delito ecológico, el requisito de vulneración de la normativa protectora del medio ambiente.

\section{LA CONSUMACIÓN}

La consumación de estos delitos contra el medio ambiente se produce en el momento en el cual se verifica el acto de contaminación que infringe la normativa medioambiental, constatando que en tal situación existe una posibilidad de perjuicio grave para el medio ambiente. Será perfectamente admisible la tentativa, siempre que se inicie la actividad contaminante pero no se llegue a verificar el concreto resultado físico-natural (v.gr. se da la orden de proceder al vertido, pero éste no llega a producirse por algún fallo o eventualidad) o cuando, aun habiéndose verificado tal resultado, no se ha constatado aún su idoneidad para dañar los sistemas naturales ${ }^{55}$. Estamos ante delitos de efectos permanentes, ya que la situación antijurídica perdura, más allá del momento de la consumación, durante todo el tiempo que persista el riesgo de grave daño para el medio ambiente $^{56}$.

\footnotetext{
${ }^{55}$ Vid. por ejemplo ALASTUEY DOBÓN, El delito cit., p. 131; MENDO ESTRELLA, El delito ecológico cit., p. 184; SERRANO TÁRRAGA / SERRANO MAÍLLO / VÁZQUEZ GONZÁLEZ, Tutela penal ambiental cit., p. 161; SILVA SÁNCHEZ, Delitos cit., p. 56. Por lo tanto, si bien es cierto que la consumación se produce con la verificación del peligro típico, ello no impide rechazar absolutamente la posibilidad de apreciar una tentativa, que podrá verificarse cuando se comienza la ejecución del delito pero no llega a producirse el riesgo exigido. Excluye las formas imperfectas de ejecución PÉREZ DE GREGORIO, J.J., "Jurisprudencia penal medioambiental (II)", La Ley, 1996-2, p. 1682, citando jurisprudencia en este sentido. Vid. críticamente con la posibilidad de apreciar una tentativa, desde una perspectiva político-criminal, GÓMEZ RIVERO, "El delito ecológico" cit., p. 91.

${ }^{56}$ Vid. GÓMEZ RIVERO, "El delito ecológico" cit., p. 91; MARTÍNEZ-BUJÁN PÉREZ, Derecho penal económico cit., p. 798; MENDO ESTRELLA, El delito ecológico cit., pp. 197-198. Puede verse la STS 26-2002 (RJ 2003\6235). MARQUĖS I BANQUĖ, "Artículo 325" cit., p. 728, lo califica como delito de estado, partiendo de que el mantenimiento de la situación antijurídica no depende de la voluntad del autor.
} 


\section{AUTORÍA Y PARTICIPACIÓN}

Las diferentes figuras delictivas incluidas en el artículo 325 son delitos comunes, de tal modo que cualquiera podrá ser su autor. La doctrina por lo general afirma que el Código acoge un "concepto extensivo de autor", ya que la conducta constitutiva del tipo básico del delito ecológico aparece definida como "provocar o realizar" vertidos, emisiones, etc. De este modo, no sólo será autor del delito quien "realice" materialmente unas emisiones o vertidos concretos, sino cualquier persona que con su intervención determine, "provoque", la posterior ejecución de esos vertidos o emisiones ${ }^{57}$. La identificación de los posibles autores en este tipo de conductas encuentra algunas dificultades, y a continuación se examinarán dos destacadas situaciones problemáticas: una de ellas consiste en la atribución de responsabilidades cuando la conducta delictiva es realizada en el ámbito de una empresa, de tal modo que habrá que determinar quién ha tenido el dominio del hecho (y por lo tanto es autor) en el marco de la estructura empresarial; la otra cuestión consiste en la dificultad de individualizar a los autores en aquellos casos, por lo general frecuentes, en que en un mismo lugar concurren acciones realizadas por diferentes sujetos, lo cual dificulta la atribución personal de responsabilidades.

\section{Determinación de la responsabilidad penal en el ámbito empresarial}

Es frecuente que los delitos contra el medio ambiente se cometan en el seno de una empresa, o que participen diferentes empresas en la ejecución de la conducta delictiva, de modo que surgirán determinados problemas de atribución de responsabilidades a las personas físicas en este ámbito ${ }^{58}$. Como ha venido manifestando la doctrina, se trata simplemente de individualizar al autor, y para ello sólo habrá que descubrir quién ha tenido el dominio del hecho, como en cualquier delito común, sin necesidad de acudir al artículo 31, como a veces hacen algunos jueces y tribunales para determinar la autoría en el marco de una estructura empresarial, ya que ese precepto pretende únicamente

\footnotetext{
${ }^{57}$ Vid. sobre esta amplia delimitación del autor del delito, GÓMEZ RIVERO, "El delito ecológico" cit., pp. 70 y 86-88; MARTÍNEZ-BUJÁN PÉREZ, Derecho penal económico cit., p. 798. Vid. considerando que no se acoge aquí un concepto extensivo de autor, BAUCELLS LLADÓS, "De los delitos" cit., pp. 1383-1384.

${ }^{58}$ Vid. sobre lo que se expondrá a continuación PUENTE ABA, "La represión penal” cit., pp. 570 ss.
} 
fijar unas reglas de determinación de la autoría en relación con los delitos especiales ${ }^{59}$. Tal interpretación se refiere a la búsqueda de la persona física responsable del hecho delictivo; si bien se trataría de una operación imprescindible en el marco de un sistema penal que optase por la responsabilidad criminal exclusiva de las personas físicas, debe tenerse en cuenta que actualmente el Ordenamiento español acepta, tras la reforma efectuada por LO 5/2010, de 22 de junio, la responsabilidad penal de las personas jurídicas.

Esta ley de reforma introduce un artículo $31 \mathrm{bis}$, que contempla la responsabilidad directa y principal de las personas jurídicas junto con la que corresponde a las personas físicas. En efecto, este precepto comienza estableciendo que las personas jurídicas serán penalmente responsables de los delitos cometidos en su nombre y en su provecho por sus representantes y administradores, y también de los cometidos por las personas físicas sometidas a la autoridad de los dirigentes de la persona jurídica, cuando estos últimos no hayan ejercido el debido control sobre sus subordinados; de esta forma, cuando el delito sea cometido en el ámbito de una empresa podrá hacerse responsables criminalmente tanto a las personas físicas que lo han ejecutado como a la propia persona jurídica. Esto ha conllevado la correlativa reforma del artículo 33, que ahora incluye un catálogo específico de sanciones propias para las personas jurídicas, que comprende desde su disolución hasta la pena de multa. Pero la reforma aún va más allá, puesto que establece la posibilidad de que las personas jurídicas sean condenadas por un delito aun cuando la concreta persona física responsable no haya sido individualizada o no haya sido posible dirigir el procedimiento contra ella. Debe señalarse que la responsabilidad penal de las personas jurídicas sólo será exigible en relación con aquellas categorías delictivas en las que el Código penal lo prevea expresamente; a este respecto, el artículo 327 del Texto punitivo establece, para los delitos contra los recursos naturales y el medio ambiente, la posibilidad de castigar penalmente a la persona jurídica, indicando asimismo aquellas sanciones que le serían aplicables ${ }^{60}$.

\footnotetext{
${ }^{59}$ Vid. al respecto BAUCELLS LLADÓS, "De los delitos” cit., pp. 1381-1382; GÓMEZ RIVERO, El régimen cit., p. 56; MATELLANES RODRÍGUEZ, Derecho penal cit., pp. 58-59; MENDO ESTRELLA, El delito ecológico cit., pp. 172-173; SILVA SÁNCHEZ, Delitos cit., pp. 26-27; ZUGALDÍA ESPINAR, J.M., "Delitos contra el medio ambiente y responsabilidad criminal de las personas jurídicas", AA.VV., Empresa y delito en el nuevo Código penal, CGPJ, Madrid, 1997, pp. 215 ss.

60 Vid. sobre la responsabilidad penal de las personas jurídicas, aplicada al delito ecológico, CARBONELL MATEU, J.C. / MORALES PRATS, F., "Responsabilidad penal de las personas jurídicas”, Álvarez García, F.J. / González Cussac, J.L. (dir.), Comentarios a la Reforma Penal de 2010,
} 
A la hora de descubrir, en el marco de la estructura empresarial, qué sujetos concretos son los auténticos responsables, lo decisivo es determinar quiénes han intervenido fácticamente en el hecho delictivo, o han tenido un dominio efectivo sobre el curso de la acción delictiva $^{61}$. Tal dominio o facultad decisoria podrá corresponder a los propios directivos de la empresa o, en virtud del fenómeno de delegación de competencias, a cualquier persona que tenga como función específica la gestión de los aspectos medioambientales dentro de la empresa. Con base en este específico funcionamiento de la actividad empresarial, puede incluso admitirse la existencia de casos en los que el subalterno desarrolla una actividad de forma totalmente neutral o estándar, lo cual determina la inexistencia de responsabilidad penal de estos sujetos y su atribución únicamente a los directivos o al personal responsable de las cuestiones medioambientales de la empresa, que son quienes adoptan la decisión delictiva y encargan la mera ejecución material mediante una actividad neutra o "fungible" (v.gr. la apertura de la vía por donde sale un vertido) ${ }^{62}$.

Centrándonos en el fenómeno de la delegación de competencias, cabe afirmar que aun en el caso de que la competencia relativa a estas actividades corresponda a un delegado

Tirant lo Blanch, Valencia, 2010, pp. 71 ss; MARQUÈS I BANQUÉ, “Artículo 325” cit., pp. 737-739; MUÑOZ CONDE, F. / GARCÍA ARÁN, M., Derecho penal. Parte general, Tirant lo Blanch, Valencia, $2010^{8}$, pp. 627 ss; ORTS BERENGUER, E. / GONZÁLEZ CUSSAC, J.L., Compendio de Derecho penal. Parte general, Tirant lo Blanch, Valencia, 2010², pp. 236 ss; ZUGALDÍA ESPINAR, J.M. (dir.), Fundamentos de Derecho penal. Parte general, Tirant lo Blanch, Valencia, $2010^{4}$, pp. $581 \mathrm{ss.}$

Vid. también las consideraciones de BAUCELLS LLADÓS, Nuevas perspectivas cit., pp. 160 ss, en relación con la conveniencia de establecer la responsabilidad penal de las personas jurídicas en el ámbito de los delitos medioambientales.

${ }^{61}$ Cfr. SILVA SÁNCHEZ, Delitos cit., p. 28, haciendo hincapié en que este criterio material es el fundamental a la hora de atribuir responsabilidades, sin que sea decisiva la ostentación de la condición formal de administrador de la empresa.

PÉREZ DE GREGORIO, J.J., "Jurisprudencia penal medioambiental”, La Ley, 1997-4, pp. 1203 ss, centra la condición de autor en el hecho de que la persona, dentro del organigrama de la empresa, ostente funciones de dirección, gestión y administración, con capacidad decisoria sobre las actividades empresariales y obligaciones de vigilancia y control sobre ellas (cita asimismo jurisprudencia que maneja estos parámetros).

Vid. también, por ejemplo, CORCOY BIDASOLO, "Protección penal” cit., p. 643, y "Artículo 325" cit., p. 741.

Vid. por ej., las manifestaciones de la STS 28-3-2003 (RJ 2003\4069), conforme a las cuales “el acusado no sólo era, desde 1983, el gerente de la empresa en la que se produjeron los vertidos, sino que siempre ejerció plenamente todas sus competencias como administrador único...; era efectivamente el único que podía autorizar los vertidos y tenía el dominio funcional del hecho y el control real y efectivo del funcionamiento de la fábrica".

${ }^{62}$ Vid. sobre esto BAUCELLS LLADÓS, "De los delitos" cit., p. 1382; MARTÍNEZ-BUJÁN PÉREZ, Derecho penal económico cit., p. 799; vid. también GÓMEZ RIVERO, "El delito ecológico" cit., pp. 8788. Vid. por ej., la STS 13-3-2000 (RJ 2000\3315) y la SAP Barcelona 23-12-2002 (JUR 2003\156212). 
en el seno de la empresa, y por ello sea considerado directamente responsable, también es posible cuestionarse si aún así los directivos delegantes tienen algún tipo de responsabilidad penal. Efectivamente, en el seno de una empresa lo común es la división de funciones y competencias, de tal modo que en principio cada sujeto será responsable por el desempeño de las tareas que tiene encomendadas; no obstante, ello no exime totalmente de responsabilidad al directivo delegante ya que, aunque no haya realizado directamente la acción prohibida, tiene unos deberes derivados de su posición de garantía inicial: principalmente le resulta exigible la adecuada elección de sus subordinados, una correcta atribución de tareas en función de las capacidades de cada subalterno, y el mantenimiento de una supervisión general sobre las tareas delegadas. Tales sujetos poseen una posición de garantía residual por ostentar la dirección suprema de la empresa; por ello, aunque no hayan concebido y ejecutado la idea de realizar la acción contaminante, son responsables en parte de tal conducta porque se trata de una actuación desarrollada en el seno de una estructura empresarial que ellos diseñan y organizan globalmente. Las exigencias de esta posición no llegan al extremo de requerir un control absoluto y continuo de todas las actividades de los delegados y subordinados en la empresa, ya que de este modo estaría vacío de contenido el propio fenómeno de delegación de competencias. Se trata simplemente del cumplimiento de ciertos deberes relacionados con la configuración óptima de la estructura empresarial, organizada en diferentes escalones jerárquicos: elección de los delegados adecuados para cada actividad concreta, suministro de información y de medios económicos necesarios para el mejor desempeño de la actuación delegada, mantenimiento de la coordinación entre los diferentes departamentos o sectores, vigilancia o supervisión de las distintas tareas encomendadas en el seno de la empresa, etc ${ }^{63}$. Aun más, se ha planteado incluso que la actividad contaminante llevada a cabo por el sujeto delegado, competente en materia medioambiental, no responda a una elección libre y consciente, sino que sea debida precisamente a que el directivo no desempeña correctamente sus deberes de control y

\footnotetext{
${ }^{63}$ Vid. BAUCELLS LLADÓS, "De los delitos” cit., p. 1382; LASCURAÍN SÁNCHEZ, J.A., "Elogio del artículo 325 del Código penal”, Jorge Barreiro, A. (dir.), Estudios sobre la protección penal del medio ambiente en el ordenamiento jurídico español, Comares, Granada, 2005, pp. 285; MUÑOZ LORENTE, J., "El cambio de criterio jurisprudencial en relación con la calificación del peligro exigido para la consumación del tipo básico de los delitos contra el medio ambiente: el artículo 325 del Código Penal y su estructura de peligro hipotético (II)", Revista interdisciplinar de Gestión Ambiental, núm. 55, 2003, p. 79; SILVA SÁNCHEZ, Delitos cit., pp. 30-31. Vid. especialmente sobre la atribución de responsabilidades en el marco empresarial, con referencia específica al ámbito medioambiental, MONTANER FERNÁNDEZ, R., Gestión empresarial y atribución de responsabilidad penal. A propósito de la gestión medioambiental, Atelier, Barcelona, 2008, pássim.
} 
supervisión: por ejemplo, porque no dota al delegado de la información o los medios necesarios para impedir el desarrollo de la acción contaminante (v.gr. se eligen materias primas que causan polución, no se colocan instalaciones depuradoras, etc.). En tal situación, podría admitirse que el delegado no tiene responsabilidad penal alguna, ya que no está dentro de su esfera de competencia la decisión sobre el desarrollo de la actividad delictiva, sino que se trataría más bien de una actuación estándar y el dominio de la acción, y por tanto la responsabilidad criminal, sería atribuible únicamente al $\operatorname{directivo~}^{64}$.

Debe señalarse que es frecuente imputar la comisión de este delito a los directivos de la empresa a título de comisión por omisión, y así se aprecia en diversas resoluciones de los jueces y tribunales. Tal opción se fundamenta en el hecho de que, si los aspectos medioambientales de la empresa se hallan en el ámbito de decisión de los dirigentes o de los sujetos con competencias al respecto, y éstos no adoptan las medidas necesarias para impedir la verificación del resultado delictivo, se les puede imputar la comisión del delito ecológico ${ }^{65}$, al margen de la presencia o ausencia de responsabilidad en sus

\footnotetext{
${ }^{64}$ Vid. SILVA SÁNCHEZ, Delitos cit., pp. 31-32. No obstante, sin duda cabría admitir la responsabilidad penal de estos delegados en el caso de que dolosamente cooperasen con los órganos directivos en el desarrollo de la actividad delictiva; cfr. SILVA SÁNCHEZ, J.M., "Criterios de asignación de responsabilidad en estructuras jerárquicas", AA.VV., Empresa y delito en el nuevo Código Penal, CGPJ, Madrid, 1997, p. 19.

GÓMEZ RIVERO, El régimen cit., p. 59, habla incluso de la posible situación de inexigibilidad en que se encontrarían los sujetos ejecutores, debido a que no actúan en una posición de plena autonomía; y asimismo de la posible apreciación de la eximente de ejercicio legítimo de un oficio.

Puede verse en la jurisprudencia, por ej., la STS 25-10-2002 (RJ 2002\10461).

${ }^{65}$ Vid. en este sentido BAUCELLS LLADÓS, "De los delitos" cit., p. 1382; BLANCO LOZANO, La tutela del agua cit., pp. 452 ss; LASCURAÍN SÁNCHEZ, “Elogio” cit., pp. 286-287; SILVA SÁNCHEZ, Delitos cit., pp. 28-29. Vid. también MENDO ESTRELLA, El delito ecológico cit., pp. 179 ss., citando jurisprudencia al respecto. Puede verse por ej. la SAP Valencia 23-6-2003 (ARP 2004159), que afirma que "la organización jerárquica de las empresas determina que no siempre la conducta puramente ejecutiva del operario subordinado sea relevante desde el punto de vista jurídico penal, sino que normalmente será mucho más importante el papel de los que estén situados jerárquicamente por encima (especialmente si se trata de quienes detentan el control efectivo de la empresa, como en el presente caso), es decir que, la conducta penalmente relevante será la de aquel que 'es responsable del ámbito de organización por ser el legitimado para configurarlo con exclusión de otras personas'. Conocida la situación generadora del deber, la omisión de las medidas que fácilmente podían haber sido puestas en práctica para la correcta eliminación de los residuos, realizada con conocimiento tanto de la propia situación generadora del deber, como de las condiciones que fundamentan su posición de garante y de la posibilidad de realizar la acción debida, determina la comisión como autor por omisión del delito contra el medio ambiente". Vid. también en el mismo sentido la SAP Baleares 21-4-2005 (ARP 2005\218).
} 
propios subordinados ${ }^{66}$. En cualquier caso también se ha puesto de relieve que no es necesario acudir a la estructura de la comisión por omisión para imputar al sujeto que ordena la actividad contaminante o al que incumple su obligación de velar por el correcto funcionamiento de la empresa (no respetando las exigencias de su posición de garantía), ya que cualquiera de estos comportamientos tendría cabida en la amplia configuración de la conducta típica como "provocación directa o indirecta" de un resultado de contaminación, de tal modo que nos encontraríamos sin más ante una autoría activa de un delito medioambiental ${ }^{67}$.

\section{Concurrencia de diferentes sujetos en la realización del hecho delictivo. Especial referencia a los casos de autoría accesoria.}

En muchos supuestos, la producción de un resultado contaminante es debida a la intervención conjunta de varios sujetos, destacadamente empresas; ello dificulta enormemente la individualización de la responsabilidad de cada uno de ellos, puesto que habrá que determinar si cada actuación individual cumple los requisitos típicos del artículo 325; si resulta que cada acción aisladamente considerada es inocua, o no se verifican en ella todos los requisitos del tipo (por ejemplo la infracción de la normativa medioambiental), no quedará más remedio que afirmar la atipicidad de las conductas ${ }^{68}$.

Los casos más sencillos serán aquellos en que se puedan apreciar distintas autorías dolosas individuales o una coautoría dolosa entre todos los intervinientes, pero sin duda son supuestos con pocas probabilidades de ser verificados: en el primer caso, habría que aislar cada acción contaminante como procedente de un único sujeto, y determinar si cumple los requisitos exigidos en el tipo ${ }^{69}$; por su parte, el caso de la coautoría tampoco

\footnotetext{
66 Pueden verse la STS 25-10-2002 (RJ 2002\10461) y la SAP Barcelona 21-11-2005 (JUR 2007\119218); sobre la primera de ellas vid. el comentario de MUÑOZ LORENTE, "El cambio (I)" cit., pp. $77 \mathrm{ss}$.

${ }^{67}$ Vid. GÓMEZ RIVERO, El régimen cit., pp. 58-59.

${ }^{68}$ Vid. sobre las posibles soluciones expuestas a continuación PUENTE ABA, "La represión penal” cit., pp. 573 ss.

Puede verse también MATELLANES RODRÍGUEZ, Derecho penal cit., p. 123; SILVA SÁNCHEZ, Delitos cit., pp. 46-47.

${ }^{69}$ Se trata de casos de indudable dificultad de prueba, y así se ha puesto de relieve en las resoluciones de los tribunales, como por ej. la SAP Barcelona 19-5-2003 (ARP 2003\636), que decreta una absolución con base en el desconocimiento de la concreta proporción de vertido tóxico correspondiente al sujeto acusado: "no descartan por completo la influencia de otros factores o elementos ajenos a la propia empresa respecto a la toxicidad detectada en las muestras tomadas en la acequia... Y si no conocemos ni
} 
sería muy imaginable en la práctica: se trataría de la coordinación de sujetos diferentes para realizar vertidos susceptibles de generar de forma conjunta un daño grave al medio ambiente.

Quizás lo más frecuente será la verificación de una "autoría accesoria dolosa": distintos sujetos, de forma individual y sin conexión entre sí, realizan acciones contaminantes (v.gr. vertidos) que, aisladamente consideradas, no suponen un peligro hipotético para el medio ambiente, pero tal idoneidad para dañar el medio natural surge precisamente de la acumulación efectiva de todas ellas ${ }^{70}$. Se trata básicamente de averiguar si puede exigirse responsabilidad penal a distintos sujetos, cada uno de los cuales realiza un comportamiento en sí mismo no peligroso para el equilibrio de los sistemas naturales, derivándose tal riesgo únicamente de la acumulación de todos ellos; en otras palabras, se trata de casos en que la peligrosidad para el medio ambiente sólo puede imputarse objetivamente al conjunto de todas las acciones contaminantes.

Así, si no existe una auténtica coautoría, y cada acción aislada no presenta la idoneidad objetiva requerida por el tipo, no cabe exigir responsabilidad penal individual por el delito ecológico $^{71}$; así, por ejemplo, en casos de vertidos tóxicos a las aguas, los tribunales han dictado sentencia absolutoria en los casos en que no se pudo probar qué

volumen del vertido ni caudal del agua es evidente que tampoco podemos valorar, con criterios objetivos, si existió o no, en el caso concreto, un grave riesgo para el ecosistema".

70 Efectivamente, la autoría accesoria dolosa implica que existen dos o más acciones separadas e insuficientes para producir el resultado, pero este último se produce como consecuencia de la conjunción de todas ellas, es decir, es imputable objetivamente a la acumulación de todas las actuaciones ejecutadas unilateralmente; vid. LUZÓN PEÑA, D.M., Curso de Derecho penal. Parte general I, Universitas, 1996, p. 510. Vid. también MIR PUIG, S., Derecho penal. Parte general, Reppertor, Barcelona, 2008 ${ }^{8}$, p. 398 , haciendo hincapié en la unilateralidad como elemento esencial de la autoría accesoria; asimismo manifiesta ZUGALDÍA ESPINAR, J.M. (dir.), Derecho penal. Parte general, Tirant lo Blanch, Valencia, 2004², pp. 719-720, (vid. asimismo ZUGALDÍA ESPINAR, Fundamentos cit., p. 406), que en estos casos cada uno de los intervinientes responde individualmente de su propia actuación. Existe además la posibilidad de apreciar una autoría accesoria imprudente, es decir, un supuesto en que dos o más acciones descuidadas, efectuadas separadamente, sin consciencia ni acuerdo recíprocos, codeterminan objetivamente el hecho (vid. LUZÓN PEÑA, Curso cit., p. 510). Un ejemplo de este tipo de autoría lo tenemos en el conocido caso del Prestige, que provocó una grave contaminación con fuel, principalmente en las costas gallegas, a partir del día 13 de noviembre de 2002. Podemos identificar diferentes empresas relacionadas con el transporte y gestión del fuel causante de la polución: la armadora propietaria del buque, la sociedad operadora, la fletadora de la carga, la clasificadora y, por último, la "empresa" constituida por el capitán del buque y la tripulación a su cargo. En un caso como este es difícil imputar la realización del delito imprudente a cada acción aislada, ya que, o bien el resultado es imputable objetivamente sólo a la conjunción de todas las actuaciones descuidadas, o bien cada acción individual imprudente no alcanza la gravedad necesaria para constituir delito, ya que el artículo 331 del Código penal sólo castiga la realización del delito ecológico por imprudencia "grave". Vid. sobre esto MARTÍNEZ-BUJÁN PÉREZ, C., "Os posíbeis delitos ecolóxicos do <caso Prestige>”, AA.VV., $A$ lección do "Prestige", Candeia, Santiago de Compostela, 2004, pp. 261 ss.

${ }^{71}$ Cfr. también ALASTUEY DOBÓN, El delito cit., p. 127; SILVA SÁNCHEZ, Delitos cit., pp. 46-47. 
proporción del vertido tóxico había sido originado por el sujeto acusado ${ }^{72}$. Cabría únicamente la posibilidad, en todo caso, de sancionar a cada sujeto como autor de una tentativa inidónea ${ }^{73}$ : efectivamente, puede afirmarse que en estos casos no se llega a consumar el delito por insuficiencia de los medios comisivos, ya que la acción desencadenante del vertido no produce un resultado apto para perjudicar el medio ambiente; por lo tanto, si a pesar de esta insuficiencia la acción (el vertido) parece desde un principio ("ex ante") capaz de producir el resultado, sería posible entender cometido el delito en grado de tentativa ${ }^{74}$.

Como primera hipótesis, podemos imaginar que se realiza una acción no apta para perjudicar gravemente el equilibrio de los sistemas naturales, pero como consecuencia de la presencia de otros resultados contaminantes anteriores se genera una situación de contaminación peligrosa para el medio ambiente. Poniendo como ejemplo los casos de vertidos, si un sujeto realiza o provoca un único vertido no apto para dañar el medio ambiente, es obvio que no tendrá responsabilidad penal si tal aptitud se deriva de la conjunción de su vertido con otros vertidos ya presentes en la zona, cuya existencia él desconocía. No obstante, cabe plantearse que el sujeto conozca la precaria situación del lugar donde realiza el vertido, y aún así lleve a cabo su actividad, consciente de que la adición de su conducta a los vertidos anteriores deriva en una situación de peligro inminente para el equilibrio del sistema natural.

La posibilidad de afirmar la existencia de responsabilidad penal en esta última hipótesis se apoya básicamente en el manejo de los parámetros que fundamentan el requisito típico de aptitud. Así, tal y como se ha dicho, una acción es apta para dañar el medio ambiente cuando, por ejemplo, existe una ley científica según la cual es altamente probable que, como consecuencia de una acción semejante, se va a producir un daño medioambiental. Pues bien, otro criterio que permite afirmar la aptitud de una acción para perjudicar un ecosistema podría ser la existencia de un determinado nivel de polución en la zona: así, por ejemplo, aunque un vertido aisladamente considerado puede considerarse inocuo,

\footnotetext{
72 Vid. las SSAP Barcelona 19-5-2003 (ARP 2003\636) y Barcelona 19-10-2001 (JUR 2002\16421), Granada 29-4-2002 (JUR 2002\142891), Lugo 31-3-2001 (JUR 2001\186613) y 17-9-1999 (ARP 1999\3353) y Asturias 31-10-2002 (JUR 2003\13028).

${ }^{73}$ Acepta esta posibilidad, en casos de autoría accesoria dolosa, LUZÓN PEÑA, Curso cit., p. 510.

${ }^{74}$ Vid. ZUGALDÍA ESPINAR, Derecho penal cit., pp. 687-691, sobre la punibilidad de las tentativas no absolutamente inidóneas, es decir, aquellas que consisten en "acciones ex ante idóneas o capaces de causar el resultado perseguido” (vid. también en ZUGALDÍA ESPINAR, Fundamentos cit., p. 388).
} 
resulta apto para causar un daño porque se realiza en un lugar que potencia su dañosidad. Siendo este un criterio que permite afirmar la idoneidad objetiva de la acción para perjudicar gravemente el medio ambiente, debe recordarse la necesidad de que esta situación sea conocida por el autor. Así, será necesario constatar que el sujeto conocía las especiales características de lugar donde llevaba a cabo su conducta, y que dotaban a su actuación de la aptitud necesaria para perjudicar el medio ambiente ${ }^{75}$.

Cabría plantearse también la posibilidad algo más remota de que un sujeto ejecutase una acción no apta para contaminar, pero cuya aptitud se derivaría no de su adición a resultados anteriores, sino de la futura realización de actos de similares características. En principio, el absoluto desconocimiento de este evento futuro determinaría la irresponsabilidad penal del autor de una acción que por sí sola no es apta para dañar el medio ambiente ${ }^{76}$. Podría llegar a demostrarse, por el contrario, que el sujeto sí sabía que posteriormente se producirían otros resultados en ese mismo lugar, determinantes de la creación de un auténtico riesgo para el medio ambiente. El conocimiento de la producción de una circunstancia fundamentadora de la existencia del peligro hipotético

\footnotetext{
${ }^{75}$ ALASTUEY DOBÓN, El delito cit., p. 130, afirma que si el autor de un vertido desconocía el estado del agua, previamente dañada por otros vertidos, podrá atribuírsele responsabilidad penal a título de imprudencia. Debe entenderse que tal posibilidad será factible siempre y cuando se demuestre que tal desconocimiento responde a una imprudencia grave por parte del sujeto (artículo 331 en relación con el artículo 325), es decir, que se ha infringido un deber de cuidado consistente en no adoptar las precauciones necesarias para evitar la realización del vertido peligroso; vid. sobre los elementos necesarios para reconocer la comisión de un delito ecológico imprudente, MARTÍNEZ-BUJÁN PÉREZ, "Os posíbeis delitos" cit., pp. 235 ss.

${ }^{76}$ ALASTUEY DOBÓN, El delito cit., pp. 128-130, manifiesta que podría haber responsabilidad penal imprudente si un sujeto que realiza un vertido no se plantea la futura producción de más vertidos por terceros, siendo ello objetivamente previsible. Ciertamente, habría que examinar cada caso concreto y ver si esta falta de previsibilidad supone una infracción del deber de cuidado exigible en este tipo de actividades ; recuérdese que antes de adoptar una decisión peligrosa como es la realización de un vertido, es necesario adoptar determinadas medidas previas de información y preparación, y con base en estos conocimientos ha de examinarse si de la realización de la conducta prevista puede derivarse el resultado delictivo (esto es, la verificación de un vertido peligroso para el medio ambiente) (vid. sobre los parámetros definidores de la imprudencia penal MARTÍNEZ-BUJÁN PÉREZ, "Os posíbeis delitos" cit., pp. 235 ss). En principio, por lo tanto, parece que la conducta descrita sí podría constituir una imprudencia penal; así, por ej., en esta línea DE LA CUESTA AGUADO, La prueba cit., pp. 16-17, manifiesta que en estos casos, si el autor de un vertido desconoce pero cuenta con la producción de vertidos posteriores, cabría atribuirle responsabilidad penal a título de imprudencia o incluso de dolo eventual. No obstante, no debe olvidarse que la imprudencia propia del delito ecológico es de naturaleza "grave", lo cual exige una relevante infracción de la norma de cuidado debido (vid. también MARTíNEZBUJÁN PÉREZ, "Os posíbeis delitos" cit., pp. 245-246); así, habría que ver, por ejemplo, si el hecho de no prever la posibilidad de los futuros vertidos implica una alta probabilidad de producción del evento delictivo.
} 
para el medio ambiente permitiría afirmar la responsabilidad penal de esta persona como autora de un delito ecológico ${ }^{77}$.

Como conclusión de todo lo manifestado, conviene resaltar que surgirán importantes problemas de prueba a la hora de calificar correctamente las posibles formas de actuación del autor de una acción contaminante. Por una parte, existirá la dificultad de constatar los parámetros que permiten afirmar el cumplimiento del requisito típico de aptitud para perjudicar el medio ambiente; resumiendo lo dicho, tal prueba no será tarea difícil cuando ya se han producido daños efectivos, pero surgen dificultades cuando éstos todavía no se han originado o cuando su causación es debida posiblemente a la concurrencia de más resultados anteriores o posteriores al que resulta objeto de enjuiciamiento. Por otra parte, surge también la dificultad de probar los posibles conocimientos del autor sobre la concurrencia de todos los elementos determinantes de la ilicitud penal de su conducta, que serán determinantes a la hora de establecer si el delito ha sido cometido a título de dolo (directo o eventual) o de imprudencia.

\section{LAS CONSECUENCIAS JURÍDICAS.}

Habrá que distinguir las consecuencias jurídicas del delito previstas en las dos figuras delictivas que se contienen en el artículo 325. En primer lugar, en el tipo del inciso primero del artículo 325 se establece una pena de prisión de dos a cinco años ${ }^{78}$, multa de ocho a veinticuatro meses e inhabilitación especial para profesión u oficio por tiempo de uno a tres años; y para el tipo del inciso segundo se prevén las mismas penas que en el inciso primero, pero en su mitad superior. Finalmente, como ya se ha indicado, no deben olvidarse las previsiones del artículo 327, que establece determinadas sanciones

\footnotetext{
${ }^{77}$ Vid. ALASTUEY DOBÓN, El delito cit., ibídem. La autora plantea una última posibilidad en este grupo de casos de realización de un vertido no apto para dañar el medio ambiente, pero cuya aptitud para tal fin se deriva de la adición de vertidos posteriores: se trata del supuesto en que el sujeto no cuenta con la producción de estos futuros vertidos, pero cree que aquel que él mismo realiza ya es apto para perjudicar gravemente el sistema natural. Afirma la autora que cabría exigir al menos responsabilidad penal por comisión del delito ecológico en grado de tentativa, es decir, "en este caso, si una persona inteligente, situada en el momento en que aquél iba a dar comienzo a la acción, hubiese llegado a la misma conclusión, la acción será peligrosa y su autor responderá por tentativa, pero no por el delito doloso consumado" (ALASTUEY DOBÓN, El delito cit., p. 130). Estaríamos realmente ante un "error al revés" (el sujeto cree que concurre un elemento del tipo que no se verifica en la realidad), que supone la ejecución de una tentativa inidónea, es decir, se da inicio a la ejecución de un delito que no llega a consumarse por insuficiencia de medios comisivos; vid. sobre este tratamiento del error al revés y de la tentativa inidónea MIR PUIG, Derecho penal cit., pp. 356 ss; LUZÓN PEÑA, Curso cit., pp. 468-469.

${ }^{78}$ Previamente a la LO 5/2010, la pena de prisión tenía una duración de seis meses a cuatro años.
} 
para los casos en que una persona jurídica sea considerada penalmente responsable del delito ecológico.

En relación con estas figuras delictivas, habrá que tener en cuenta las Disposiciones comunes contenidas al final del Título relativo a los delitos contra el patrimonio histórico, la ordenación del territorio y el medio ambiente. Particularmente se deberá atender al artículo 338, según el cual se aplicarán las penas superiores en grado a las respectivamente previstas en los casos en que la conducta delictiva afecte a espacios naturales protegidos. Por otra parte, también podrá ser tomado en consideración el artículo 340 que, como se verá al analizar este precepto, establece una atenuación de la pena para los casos de reparación voluntaria del daño medioambiental causado.

\section{SITUACIONES CONCURSALES}

Los dos tipos penales contenidos en el artículo 325, al ser delitos de peligro hipotético, pueden dar lugar a un concurso de delitos con distintas infracciones lesivas, como el homicidio, las lesiones o los daños ${ }^{79}$; debería calificarse como un concurso real, teniendo en cuenta que, si bien la acción es la misma, nos encontramos ante resultados distintos (muertes, lesiones, peligro medioambiental), que determinan la ausencia de identidad total de hechos típicos ${ }^{80}$.

Se ha planteado la posibilidad de admitir la figura del delito continuado, por ejemplo en los casos en que hay una reiteración de actos contaminantes realizados por un mismo sujeto. Aunque hay distintas opiniones jurisprudenciales, mayoritariamente el Tribunal Supremo estima que no cabe apreciar la figura del delito continuado, ya que el tipo penal utiliza un concepto global de acción, refiriéndose a la provocación de

\footnotetext{
79 Vid. MARTÍNEZ-BUJÁN PÉREZ, Derecho penal económico cit., p. 799; DE LA MATA BARRANCO, "Protección penal del ambiente" cit., pp. 228-229; MENDO ESTRELLA, El delito ecológico cit., pp. 186-187; MUÑOZ CONDE, Derecho penal cit., p. 594. Vid. también QUERALT JIMÉNEZ, Derecho penal cit., p. 874, citando jurisprudencia.

${ }^{80}$ Vid. SILVA SÁNCHEZ, Delitos cit., pp. 140-414. En cambio, califican este concurso como ideal BAUCELLS LLADÓS, "De los delitos" cit., p. 1397; CORCOY BIDASOLO, "Artículo 325” cit., p. 741; GÓMEZ RIVERO, "El delito ecológico" cit., pp. 92-93; MENDO ESTRELLA, El delito ecológico cit., p. 185; MUÑOZ CONDE, Derecho penal cit., p. 594. Puede verse aquí, a título de ejemplo, la SAP Barcelona 2-1-2009 (ARP 2009\310), relativa a un caso de contaminación acústica.
} 
"emisiones", "vertidos", etc., en general, sin identificar cada acción aisladamente considerada como un único delito ${ }^{81}$.

\section{BIBLIOGRAFÍA}

ALASTUEY DOBÓN, M.C., El delito de contaminación ambiental (artículo 325.1 del Código penal), Comares, Granada, 2004.

BAUCELLS LLADÓS, J., "De los delitos relativos a la ordenación del territorio y la protección del patrimonio histórico y del medio ambiente", Córdoba Roda, J. / García Arán, M. (dir.), Comentarios al Código Penal. Parte especial. Tomo I, Marcial Pons, Madrid, 2004, pp. 1347-1477.

- Nuevas perspectivas de la política criminal europea en materia ambiental, Atelier, Barcelona, 2007.

BERDUGO GÓMEZ DE LA TORRE, I., "La protección penal del medio ambiente. Algunas cuestiones generales", Muñoz Conde, F., (dir.), Problemas actuales del Derecho penal y de la Criminología. Estudios penales en memoria de la Profesora Dra. María del Mar Díaz Pita, Tirant lo Blanch, Valencia, 2008, pp. 997-1008.

BOIX REIG, J. / JAREÑO LEAL, A., "De los delitos contra los recursos naturales y el medio ambiente", Vives Antón, T.S. (coord.), Comentarios al Código Penal de 1995, Volumen I, Tirant lo Blanch, Valencia, 1996, pp. 1591-1599.

BLANCO LOZANO, C., El delito ecológico. Manual operativo, Montecorvo, Madrid, 1997.

- La protección del medio ambiente en el Derecho penal español y comparado, Comares, Granada, 1997.

81 Cfr. MARTÍNEZ-BUJÁN PÉREZ, Derecho penal económico cit., p. 799; DE LA MATA BARRANCO, "Protección penal del ambiente" cit., p. 243; MATELLANES RODRÍGUEZ, Derecho penal cit., pp. 123-124; MUÑOZ LORENTE, “Algunas consideraciones” cit., p. 205; MARQUĖS I BANQUÉ, “Artículo 325” cit., pp. 727-728; SILVA SÁNCHEZ, Delitos cit., pp. 51 ss; TERRADILLOS BASOCO, “Artículo 325” cit., p. 145.

Por el contrario, MENDO ESTRELLA, El delito ecológico cit., p. 198, y PÉREZ DE GREGORIO, "Jurisprudencia penal medioambiental (II)" cit., pp. 1683-1684, admiten la continuidad delictiva.

Pueden verse, por ejemplo, las SSTS 12-12-2000 (RJ 2000\9790) y 26-9-1994 (RJ 1994\7194), que rechazan la aplicación del delito continuado; de opinión contraria, la STS 11-2-2003 (RJ 2003\1083). 
-La tutela del agua a través del Derecho penal, Bosch, Barcelona, 2000.

CARBONELL MATEU, J.C. / MORALES PRATS, F., "Responsabilidad penal de las personas jurídicas”, Álvarez García, F.J. / González Cussac, J.L. (dir.), Comentarios a la Reforma Penal de 2010, Tirant lo Blanch, Valencia, 2010, pp. 55-86.

COLÁS TURÉGANO, A., "Algunas consideraciones sobre los delitos contra el medio ambiente en el CP de 1995 (C. III del T. XVI del L. II)", AAVV, Estudios jurídicos en memoria del profesor Dr. D. José Ramón Casabó Ruiz, Universidad de Valencia, 1997, Volumen I, pp. 419-446.

CORCOY BIDASOLO, M., "Protección penal del medio ambiente: legitimidad y alcance. Competencia penal y administrativa", Mir Puig, S. / Modolell González, J.L. / Gallego Soler, J.I. / Bello Rengifo, C.S. (coord.), Estudios de Derecho penal económico, Livrosca, Caracas, 2002, pp. 599-648.

- “Artículo 325”, Corcoy Bidasolo, M. / Mir Puig, S. (dir.), Comentarios al Código penal. Reforma LO 5/2010, Tirant lo Blanch, Valencia, 2011, pp. 737-742.

CORCOY BIDASOLO, M. / VIVES - REGO, J., "La evaluación del riesgo y del impacto (o daño) en el delito ecológico: aspectos jurídicos y forenses", Revista del Poder Judicial, núm. 83, 2006, pp. 91-128.

DE LA CUESTA AGUADO, P., La prueba en el delito ecológico, Tecnos, Madrid, 1995.

- Causalidad de los delitos contra el medio ambiente, Tirant lo Blanch, Valencia, 1999.

DE LA CUESTA ARZAMENDI, J.L., "Cuestiones dogmáticas relativas al delito de contaminación ambiental”, Revista penal, núm. 4, 1999, pp. 30-41.

ESCAJEDO SAN EPIFANIO, L., El medio ambiente en la crisis del Estado social. Su protección penal simbólica, Ecorama, Granada, 2006.

GARCÍA RIVAS, N., Delito ecológico. Estructura y aplicación judicial, Praxis, Barcelona, 1998.

GÓMEZ RIVERO, M.C., El régimen de autorizaciones en los delitos relativos a la protección del medio ambiente y ordenación del territorio, Tirant lo Blanch, Valencia, 2000 . 
- "El delito ecológico", Martos Núñez, J.A. (dir.), Derecho penal ambiental, Exlibris, Madrid, 2006, pp. 55-117.

GRANADOS PÉREZ, C., "La contaminación acústica como modalidad de delito contra el medio ambiente", López Barja de Quiroga, J. / Zugaldía Espinar, J.M. (coord.), Dogmática y ley penal. Libro Homenaje a Enrique Bacigalupo, Marcial Pons, Madrid, 2004, Tomo II, pp. 969-991.

HORMAZÁBAL MALAREE, H., "El principio de lesividad y el delito ecológico", Quintero Olivares, G. / Morales Prats, F. (coord.), El nuevo Derecho penal español. Estudios penales en memoria del Profesor José Manuel Valle Muñiz, Aranzadi, Cizur Menor, 2001, pp. 1417-1428.

HUERTA TOCILDO, S., "Principios básicos del Derecho penal y artículo 325 del Código Penal", Revista penal, núm. 8, 2001, pp. 39-52.

JORGE BARREIRO, A., "El bien jurídico protegido en los delitos contra el medio ambiente en el CP de 1995", Jorge Barreiro, A. (dir.), Estudios sobre la protección penal del medio ambiente en el ordenamiento jurídico español, Comares, Granada, 2005, pp. 1-72.

LASCURAÍN SÁNCHEZ, J.A., “ Elogio del artículo 325 del Código penal”, Jorge Barreiro, A. (dir.), Estudios sobre la protección penal del medio ambiente en el ordenamiento jurídico español, Comares, Granada, 2005, pp. 265-294.

LLORENTE SÁNCHEZ-ARJONA, M., "La prueba de la relación de causalidad en los daños ambientales”, Martos Núñez, J.A. (dir.), Derecho penal ambiental, Exlibris, Madrid, 2006, pp. 315-329.

LUZÓN PEÑA, D.M., Curso de Derecho penal. Parte general I, Universitas, 1996.

MARQUÈS I BANQUÉ, M., “Artículo 325”, Quintero Olivares, G. (dir.), Comentarios al Código Penal español. Tomo II, Aranzadi, Cizur Menor, $2011^{6}$, pp. 699-739.

MARTÍNEZ-BUJÁN PÉREZ, C., "Os posíbeis delitos ecolóxicos do <caso Prestige>”, AA.VV., A lección do "Prestige”, Candeia, Santiago de Compostela.

- Derecho penal económico y de la empresa. Parte especial, Tirant lo Blanch, Valencia, $2011^{3}$. 
MARTOS NÚÑEZ, J.A., "Introducción al Derecho penal ambiental”, Martos Núñez, J.A. (dir.), Derecho penal ambiental, Exlibris, Madrid, 2006, pp. 17-51.

- El delito de contaminación acústica, Iustel, Madrid, 2010.

DE LA MATA BARRANCO, N., Protección penal del ambiente y accesoriedad administrativa, Cedecs, Barcelona, 1996.

-“Configuración como ley penal en blanco de los delitos contra el ambiente”, AAVV, Estudios jurídicos en memoria del profesor Dr. D. José Ramón Casabó Ruiz, Universidad de Valencia, 1997, Volumen I, pp. 569-596.

- "El ambiente, como objeto de tutela penal específico y sistemáticamente autónomo, desde una concepción moderadamente antropocéntrica", Mir Puig, S. / Modolell González, J.L. / Gallego Soler, J.I. / Bello Rengifo, C.S. (coord.), Estudios de Derecho penal económico, Livrosca, Caracas, 2002, pp. 569-598.

- "Delitos contra el medio ambiente: accesoriedad administrativa", AAVV, Técnicas de investigación e infracciones medioambientales, CGPJ, Madrid, 2006, pp. 9-78.

-“Protección penal del ambiente", Serrano Piedecasas, J.R. / Demetrio Crespo, J.R. (dir.), Cuestiones actuales de Derecho penal empresarial, Colex, Madrid, 2010, pp. 221-246.

MATA Y MARTÍN, R.M., “Artículo 325”, Gómez Tomillo, M. (dir.), Comentarios al Código penal, Lex Nova, Valladolid, 2011², pp. 1271-1275.

MATELLANES RODRÍGUEZ, N., Derecho penal del medio ambiente, Iustel, Madrid, 2008.

MATEOS RODRÍGUEZ - ARIAS, A., Los delitos relativos a la protección del medio ambiente, Colex, Madrid, 1998.

MENDO ESTRELlA, A., El delito ecológico del artículo 325.1 del Código penal, Tirant lo Blanch, Valencia, 2009.

MENDOZA BUERGO, B., "El delito ecológico: configuración típica, estructuras y modelos de tipificación”, Jorge Barreiro, A. (dir.), Estudios sobre la protección penal del medio ambiente en el ordenamiento jurídico español, Comares, Granada, 2005, pp. 109-150.

MIR PUIG, S., Derecho penal. Parte general, Reppertor, Barcelona, $2008^{8}$. 
MONTANER FERNÁNDEZ, R., Gestión empresarial y atribución de responsabilidad penal. A propósito de la gestión medioambiental, Atelier, Barcelona, 2008.

MORALES PRATS, F., "La estructura del delito de contaminación ambiental. Dos cuestiones básicas: la ley penal en blanco y concepto de peligro", AAVV, Estudios jurídicos en memoria del profesor Dr. D. José Ramón Casabó Ruiz, Universidad de Valencia, 1997, Volumen II, pp. 475-500.

MUÑOZ CONDE, F., Derecho penal. Parte especial, Tirant lo Blanch, Valencia, $2010^{18}$.

MUÑOZ CONDE, F. / GARCÍA ARÁN, M., Derecho penal. Parte general, Tirant lo Blanch, Valencia, $2010^{8}$.

MUÑOZ LORENTE, J., "Algunas consideraciones sobre los delitos contra el medio ambiente en la jurisprudencia del Tribunal Supremo", Revista del Poder Judicial, núm. 67, 2002, pp. 155-214.

- "El cambio de criterio jurisprudencial en relación con la calificación del peligro exigido para la consumación del tipo básico de los delitos contra el medio ambiente: el artículo 325 del Código Penal y su estructura de peligro hipotético" (I y II), Revista interdisciplinar de gestión ambiental, núm. 54, 2003, pp. 70-84, y núm. 55, 2003, pp. $70-85$.

MUÑOZ LORENTE, J. / BAUCELLS LLADÓS, J. / FARALDO CABANA, P., "Delitos contra los recursos naturales y el medio ambiente (arts. 325, 327, 328 y 329)", Álvarez García, F.J. / González Cussac, J.L. (dir.), Comentarios a la Reforma Penal de 2010, Tirant lo Blanch, Valencia, 2010, pp. 385-398.

ORTS BERENGUER, E. / GONZÁLEZ CUSSAC, J.L., Compendio de Derecho penal. Parte general, Tirant lo Blanch, Valencia, $2010^{2}$.

PAREDES CASTAÑÓN, J.M., "Responsabilidad penal y 'nuevos riesgos': el caso de los delitos contra el medio ambiente", Actualidad Penal, 1997-1, marg. 217-227.

PÉREZ DE GREGORIO, J.J., “Jurisprudencia penal medioambiental (II)”, La Ley, 1996-2, pp. 1678-1685.

-“Jurisprudencia penal medioambiental”, La Ley, 1997-4, pp. 1203-1212. 
PUENTE ABA, L.M., "La represión penal de vertidos marinos intencionados: cuestiones relativas al riesgo de contaminación y a la atribución de responsabilidades", Meilán Gil, J.L. (dir.), Estudios sobre el régimen jurídico de los vertidos de buques en el medio marino, Aranzadi, Cizur Menor, 2006, pp. 563-576.

PUENTE ABA, L.M. / PERNAS GARCÍA, J.J., "Le Droit répressif espagnol et les déversements illicites des navires en mer", Le Droit maritime français, núm. 661, 2005, pp. 622-640.

QUERALT JIMÉNEZ, J.J., Derecho penal español. Parte especial, Atelier, Barcelona, $2008^{6}$.

RODRÍGUEZ LÓPEZ, P. Medio ambiente, territorio, urbanismo y Derecho penal, Bosch, Barcelona, 2007.

SERRANO TÁRRAGA, M.D. / SERRANO MAÍLLO, A. / VÁZQUEZ GONZÁLEZ, C., Tutela penal ambiental, Dykinson, Madrid, 2009.

SILVA SÁNCHEZ, J.M., "Criterios de asignación de responsabilidad en estructuras jerárquicas", AAVV, Empresa y delito en el nuevo Código Penal, CGPJ, Madrid, 1997, pp. 9-58.

-Delitos contra el medio ambiente, Tirant lo Blanch, Valencia, 1999.

SOSPEDRA NAVAS, F., "De los delitos contra los recursos naturales y el medio ambiente. Capítulo III", Domínguez, J.A. y otros, Delitos relativos a la ordenación del territorio y protección del patrimonio histórico, medio ambiente y contra la seguridad colectiva (delitos de riesgo catastrófico e incendios), Bosch, Barcelona, 1999, pp. 167220.

TERRADILLOS BASOCO, J., "Delitos relativos a la protección del patrimonio histórico y del medio ambiente", Terradillos Basoco, J. (ed.), Derecho penal del medio ambiente, Trotta, Madrid, 1997, pp. 35-58.

- "Artículo 325 del Código penal. Lecturas jurisprudenciales", AAVV, Técnicas de investigación e infracciones medioambientales, CGPJ, Madrid, 2006, pp. 125-160.

URRAZA ABAD, J., Delitos contra los recursos naturales y el medio ambiente, La Ley, Madrid, 2001. 
VAELLO ESQUERDO, E., "Los delitos contra el medio ambiente”, Revista Aranzadi de Derecho ambiental, núm. 7, 2005-1, pp. 15-42.

VERCHER NOGUERA, A., "Reflexión sobre las emisiones y vertidos en los delitos contra el medio ambiente y algunos aspectos determinantes en los mismos", Revista penal, núm. 7, 2001, pp. 99-108.

-“Responsabilidad penal ambiental”, Vercher Noguera, A. / Díez-Picazo Giménez, G. / Castañón del Valle, M., Responsabilidad ambiental penal, civil y administrativa, La Ley, Madrid, 2003, pp. 11-87.

ZUGALDÍA ESPINAR, J.M., "Delitos contra el medio ambiente y responsabilidad criminal de las personas jurídicas", AAVV, Empresa y delito en el nuevo Código penal, CGPJ, Madrid, 1997, pp. 211-239.

ZUGALDÍA ESPINAR, J.M. (dir.), Derecho penal. Parte general, Tirant lo Blanch, Valencia, $2004^{2}$.

- Fundamentos de Derecho penal. Parte general, Tirant lo Blanch, Valencia, $2010^{4}$. 